\title{
Hyaluronan Deficiency Due to Has3 Knock-Out Causes Altered Neuronal Activity and Seizures via Reduction in Brain Extracellular Space
}

\author{
Amaia M. Arranz, ${ }^{1}$ Katherine L. Perkins, ${ }^{2,3}$ Fumitoshi Irie, ${ }^{1}$ David P. Lewis, ${ }^{4,5}$ Jan Hrabe, ${ }^{4,5}$ Fanrong Xiao, ${ }^{4}$ Naoki Itano, ${ }^{6}$ \\ Koji Kimata, ${ }^{7}$ Sabina Hrabetova, ${ }^{3,4}$ and Yu Yamaguchi ${ }^{1}$ \\ ${ }^{1}$ Genetic Disease Program, Sanford Children's Health Research Center, Sanford-Burnham Medical Research Institute, La Jolla, California 92037, \\ ${ }^{2}$ Department of Physiology and Pharmacology, ${ }^{3}$ The Robert F. Furchgott Center for Neural and Behavioral Science, and ${ }^{4}$ Department of Cell Biology, SUNY \\ Downstate Medical Center, Brooklyn, New York 11203, ${ }^{5}$ Center for Advanced Brain Imaging, Nathan S. Kline Institute for Psychiatric Research, \\ Orangeburg, New York 10962, ${ }^{\circ}$ Department of Molecular Biosciences, Kyoto Sangyo University, Kyoto 603-8555, Japan, and ${ }^{7}$ Research Complex for \\ Medicine Frontiers, Aichi Medical University, Aichi 480-1195, Japan
}

Hyaluronan (HA), a large anionic polysaccharide (glycosaminoglycan), is a major constituent of the extracellular matrix of the adult brain. To address its function, we examined the neurophysiology of knock-out mice deficient in hyaluronan synthase (Has) genes. Here we report that these Has mutant mice are prone to epileptic seizures, and that in Has $3^{-1-}$ mice, this phenotype is likely derived from a reduction in the size of the brain extracellular space (ECS). Among the three Has knock-out models, namely Has $3^{-1-}, H a s 1^{-1-}$, and $\mathrm{Has} 2^{C K O}$, the seizures were most prevalent in $\mathrm{Has}^{-1-}$ mice, which also showed the greatest HA reduction in the hippocampus. Electrophysiology in $\mathrm{Has}^{-1-}$ brain slices demonstrated spontaneous epileptiform activity in CA1 pyramidal neurons, while histological analysis revealed an increase in cell packing in the CA1 stratum pyramidale. Imaging of the diffusion of a fluorescent marker revealed that the transit of molecules through the ECS of this layer was reduced. Quantitative analysis of ECS by the real-time iontophoretic method demonstrated that ECS volume was selectively reduced in the stratum pyramidale by $\sim 40 \%$ in $\mathrm{Has}^{-/-}$mice. Finally, osmotic manipulation experiments in brain slices from $\mathrm{Has3}^{-I-}$ and wild-type mice provided evidence for a causal link between ECS volume and epileptiform activity. Our results provide the first direct evidence for the physiological role of HA in the regulation of ECS volume, and suggest that HA-based preservation of ECS volume may offer a novel avenue for development of antiepileptogenic treatments.

\section{Introduction}

Epilepsy is one of the most common neurological disorders, yet it remains among the least understood of major chronic conditions. It is characterized by recurrent spontaneous seizures caused by abnormal synchronous firing of neurons. Although changes in synaptic transmission can lead to epileptic hypersyn-

\footnotetext{
Received Aug. 8, 2013; revised Feb. 18, 2014; accepted March 24, 2014.
}

Author contributions: S.H. and Y.Y. designed research; A.M.A., K.L.P., F.I., D.P.L., J.H., F.X., and S.H. performed research; N.I. and K.K. contributed unpublished reagents/analytic tools; A.M.A., K.L.P., F.I., D.P.L., S.H., and Y.Y. analyzed data; A.M.A., K.L.P., S.H. and Y.Y. wrote the paper.

This work was supported by National Institutes of Health Grants R01 NS41332 (Y.Y.), P01 HD25938 (Y.Y.), R56 NS047557 (S.H.), R01 NS047557 (S.H.); Sanford (enter Investigator Grant (Y.Y.); and the Pilot Project award from the College of Medicine's Research Investment Initiative program, SUNY Downstate Medical Center (K.L.P. and S.H.). A.M.A. was the recipient of a postdoctoral fellowship from MICINN of Spain, and F.X. was the recipient of a Postdoctoral Supplement award from the College of Medicine's Research Investment Initiative program, SUNY Downstate Medical Center. We thank John McDonald for providing Has ${ }^{-1-} ; \mathrm{Has}^{-1-}$ compound mutant mice, Tallie Z. Baram for advice on seizure analysis, Larkin Slater for animal maintenance and care, and Christopher Schwalen for assistance with ISM fabrication and RTI experiments.

The authors declare no competing financial interests.

Correspondence should be addressed to either of the following: Sabina Hrabetova, SUNY Downstate Medical Center, 450 Clarkson Avenue, Box 5, Brooklyn, NY 11203, E-mail: sabina.hrabetova@downstate.edu; or Yu Yamaguchi, Sanford-Burnham Medical Research Institute, 10901 North Torrey Pines Road, La Jolla, CA 92037, E-mail: yyamaguchi@sanfordburnham.org.

DOI:10.1523/JNEUROSCI.3458-13.2014

Copyright $\odot 2014$ the authors $\quad 0270-6474 / 14 / 346164-13 \$ 15.00 / 0$ chrony, nonsynaptic mechanisms, such as ionic changes in the extracellular solution and enhanced electric field effects and ephaptic interactions (Jefferys, 1995), can also play a role in the generation of epileptiform activity (Traynelis and Dingledine, 1989; Dudek et al., 1998; Margineanu, 2010).

Ionic effects, electric field effects, and ephaptic interactions depend on the extracellular space (ECS). The ECS comprises a system of contiguous narrow spaces interposed between the brain cells, filled with ionic solution and macromolecules of the extracellular matrix. ECS structure is characterized by two macroscopic parameters: volume fraction $\alpha$, which is defined as the proportion of the tissue occupied by the ECS; and diffusion permeability $\theta$, which quantifies how the diffusion process in an ECS microenvironment is slowed down compared with an obstaclefree medium (Nicholson, 2001; Hrabe et al., 2004). Changes in the structure of ECS influence accumulation and clearance of ions and neuroactive substances as well as the effectiveness of electric-field effects and ephaptic interactions, and thus affect the excitability of the neuronal population (Syková and Nicholson, 2008). It has been speculated that matrix macromolecules play a role in the maintenance of $\alpha$ and $\theta$ (Syková and Nicholson, 2008).

Hyaluronan (HA), a large anionic polysaccharide (glycosaminoglycan), is a major component of extracellular matrices 
(ECMs). Although HA is ubiquitous in various organs and tissues, the brain is one of the organs that contains high levels of HA (Fraser et al., 1997). With its pronounced hydration capacity, HA occupies a very large molecular domain in solution and forms a porous meshwork in the extracellular matrix that exerts pressure on surrounding cells (Toole, 2000, 2004). In mammalian cells, there are three hyaluronan synthases, namely HAS1, HAS2, and HAS3, which are channel-like transmembrane molecules residing on the plasma membrane. HA is extruded directly into the ECM through the pore of these HAS molecules while it is being synthesized. This mode of synthesis is thought to allow direct and rapid modulation of the hydrated property of the microenvironment surrounding cells (Toole, 2004).

Because of its unique physicochemical property, we hypothesize that HA plays a key role in the regulation of ECS in the adult brain. In this paper, we show that mutant mice deficient in Has genes, especially $\mathrm{Has}^{-1-}$ mice, exhibit an epileptic phenotype. The hippocampal CA1 region of Has $3^{-1-}$ mice shows synchronous firing in a population of pyramidal cells, along with a pronounced reduction in the level of tissue HA. Quantitative analysis of ECS by the real-time iontophoretic method revealed that the ECS volume in the CA1 stratum pyramidale of $\mathrm{Has}^{-1-}$ mice is significantly reduced. Our data indicate that HA plays a key role in the maintenance of ECS in this region and that its deficit leads to altered neuronal activity and epilepsy.

\section{Materials and Methods}

Mice. Mouse Has1- (Mack et al., 2012) and Has3-null (Bai et al., 2005) alleles were obtained from Dr John McDonald (Mayo Clinic, Scottsdale, AZ) as $H a s 1^{-1-} ; \mathrm{Has}^{-1-}$ compound mutant mice, from which $\mathrm{Hasl}^{-1-}$ and $\mathrm{Has}^{-1-}$ mice were segregated for this study. As reported previously (Bai et al., 2005; Mack et al., 2012), Has ${ }^{-1-}, \mathrm{Has}^{-1-}$, and Has ${ }^{-1-}$;Has3 $3^{-1-}$ mice exhibited no apparent developmental abnormalities and had normal life spans. Because $\mathrm{Has}^{-1-}$ mice are embryonic lethal (Camenisch et al., 2000), brain-targeted conditional Has2 knockout mice $\left(\operatorname{Has} 2^{C K O}\right)$ were generated using the conditional Has2-null allele (Matsumoto et al., 2009) and the nestin-Cre transgene (Tronche et al., 1999). Like Has1 ${ }^{-1-}$ and Has3 ${ }^{-1-}$ mice, Has $2^{C K O}$ mice were born and grew normally with no apparent morphological defects in their brains. All mutant and WT control mice used in this study were in $100 \%$ C57BL/6 background. Both male and female mice were used in the study. Mice were bred at Sanford-Burnham Medical Research Institute (SBMRI) and adult animals were shipped to SUNY Downstate Medical Center when needed. All protocols for animal use were in accordance with NIH guidelines and local IACUC regulations of SBMRI and SUNY Downstate Medical Center.

HISS test. The handling-induced seizure susceptibility (HISS) test (Todorova et al., 1999) was used to examine seizure susceptibility in mice at 3-4 months of age. The test consisted of two handling trials, separated by $30 \mathrm{~min}$, in which the mouse was held by the tail $15 \mathrm{~cm}$ above the cage for 30 or $15 \mathrm{~s}$ and then returned to its home cage. Behavior of mice was video recorded immediately after cage changing. The test was repeated after 1 week. Mice had no routine cage changing for at least 1 week before testing. Mice were diagnosed to be seizure-susceptible if they exhibited behaviors ranging from immobility and/or head clonus to tonic-clonic movements (Todorova et al., 1999).

Video-electroencephalogram monitoring. Behavioral and electroencephalogram (EEG) observations were made by using the Pinnacle 8200 three-channel monitoring system with simultaneous video recording (Pinnacle Technology). For this analysis, mice at 3-4 months of age were surgically implanted in the left and right frontoparietal cortex with electrodes. Briefly, mice were anesthetized and the skull surface was exposed with a single rostral/caudal incision, cleaned of all connective tissue, and dried. A headmount was attached to the skull with cyanoacrylate, and four holes were drilled to place the sterile stainless steel screw recording electrodes epidurally (two placed $2 \mathrm{~mm}$ anterior to bregma, and two
Table 1. Occurrence of induced and spontaneous seizures in Has mutant mice

\begin{tabular}{|c|c|c|c|c|c|c|}
\hline & \multicolumn{2}{|c|}{ Induced by handling ${ }^{a}$} & \multicolumn{4}{|c|}{ 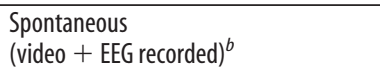 } \\
\hline & WT & $\operatorname{Has} 1^{-1-} ; \operatorname{Has}^{-1-}$ & WT & Has1 $1^{-1-}$ & $\operatorname{Has} 2^{\text {CKO }}$ & $\mathrm{Has3}^{-1-}$ \\
\hline Total mice tested & 29 & 40 & 10 & 7 & 8 & 9 \\
\hline $\begin{array}{l}\text { Mice with } \\
\text { seizures (no.) }\end{array}$ & 0 & 19 & 0 & 1 & 2 & 5 \\
\hline $\begin{array}{l}\text { Mice with } \\
\text { seizures (\%) }\end{array}$ & 0 & 47.5 & 0 & 14.3 & 25.0 & 55.6 \\
\hline
\end{tabular}

$\overline{\text { a Seizures were induced using the HISS test (Todorova et al., 1999) and video-recorded. Mice were diagnosed to be }}$ seizure-susceptible when they exhibited behaviors ranging from immobility followed by head clonus to tonic-clonic behavior.

${ }^{b}$ Spontaneous epileptic seizures were detected by simultaneous video-EEG recording. Mice were diagnosed as epileptic when they exhibited during $24 \mathrm{~h}$ recording session at least one abnormal EEG episode that lasted at least $5 \mathrm{~s}$ and was accompanied by behavioral seizures.

Table 2. Summary of electrographic seizures observed in Has mutant mice

\begin{tabular}{cccl}
\hline Animal & Duration $(\mathrm{s})^{*}$ & Frequency (per 24h)* & Seizure score $^{* *}$ \\
\hline Has3 $^{-/-}$ & & & \\
1 & $31.4 \pm 7.8$ & $4.3 \pm 1.4$ & Grade IV \\
2 & $12.3 \pm 6.8$ & $1.5 \pm 0.5$ & Grade IV \\
3 & $11.3 \pm 2.1$ & $2.7 \pm 0.3$ & Grade IV \\
4 & $6.1 \pm 0.1$ & $3.0 \pm 1.0$ & Grade III \\
5 & $6.2 \pm 0.4$ & $1.5 \pm 0.5$ & Grade III \\
Has2 $^{\text {(KO }}$ & $17.5 \pm 4.9$ & $2.0 \pm 2.0$ & \\
1 & $7.3 \pm 0.3$ & $1.0 \pm 1.0$ & Grade III \\
2 & & & Grade III \\
Has1 $^{-1-}$ & $11.6 \pm 3.6$ & $4.0 \pm 1.0$ & Grade III \\
1 & & & \\
\hline
\end{tabular}

*Duration and frequency data are shown as mean \pm SEM.

**See Materials and Methods for the criteria used to score electrographic seizures.

placed $4 \mathrm{~mm}$ posterior to bregma; each 1-2 $\mathrm{mm}$ lateral to the sagittal suture). After surgery, mice were allowed to recover for $7 \mathrm{~d}$ before initiation of the simultaneous video-EEG monitoring. For monitoring, a preamplifier was connected to the headmount and a commutator, which was attached to the Data Acquisition and Control System (Pinnacle Technology). Simultaneous video recording for analysis of the behavior was obtained using Sony CCD-TRV328 video camera linked via a port to a PC. Each mouse was subjected to two nonconsecutive $24 \mathrm{~h}$ video-EEG monitoring sessions. Recordings were sampled at $400 \mathrm{~Hz}$ and low-pass filtering was done at $55 \mathrm{~Hz}$ (EEG). Amplified EEG signals were collected, digitized, and analyzed with the Sirenia software package (Pinnacle Technology). EEG signals were rated according to the following criteria, based on Baraban et al. (2009): grade I, basic background, no epileptiform spikes; grade II, mostly normal background, some high voltage spikes; grade III, mostly abnormal background with low-frequency, high voltage spiking; and grade IV, high-frequency, high voltage synchronized polyspike waves with amplitude at least three times greater than the baseline. Only abnormal EEG events of grade III or IV that lasted $\geq 5 \mathrm{~s}$ and were accompanied by behavioral seizures were included in the data tables (Tables 1,2).

Histology and immunohistochemistry. For HA and perineuronal nets (PNNs) staining, mice were transcardially perfused with PBS followed by $4 \%$ paraformaldehyde in PBS. Brains were removed, postfixed overnight in $4 \%$ paraformaldehyde, and transferred to $10 \%$ and then $30 \%$ sucrose in PBS at $4^{\circ} \mathrm{C}$. Coronal sections ( $30 \mu \mathrm{m}$ thick) were cut on a cryostat (Leica). Free-floating sections were incubated for $2 \mathrm{~h}$ with Wisteria floribunda agglutinin (WFA; FITC-labeled, 1:500; EY Laboratories) to visualize PNNs. Staining of HA was performed by incubating free-floating sections with biotinylated hyaluronan-binding protein (HABP; $10 \mu \mathrm{g}$ / $\mathrm{ml}$; Seikagaku) in $3 \% \mathrm{BSA}$ in PBS overnight at $4^{\circ} \mathrm{C}$, followed by washing and incubation with AlexaFluor 488-conjugated streptavidin (Life Technologies) for $2 \mathrm{~h}$ at room temperature. For immunohistochemistry, freefloating sections were blocked with either $3 \%$ normal goat serum and $0.2 \%$ Triton X-100 in PBS, or 3\% BSA and $0.2 \%$ Triton X-100 in TBS for $1 \mathrm{~h}$ at room temperature. Sections were incubated overnight at $4^{\circ} \mathrm{C}$ with 
Table 3. ECS parameters measured with the RTI method in the CA1 region of hippocampus in mouse brain slices

\begin{tabular}{|c|c|c|c|c|c|c|c|}
\hline Genotype & Layer & $\alpha$ & & $\theta$ & & $n$ & No. of slices \\
\hline \multirow{3}{*}{ WT } & SR & $0.207 \pm 0.009$ & & $0.474 \pm 0.020$ & \multirow{3}{*}{ * } & 12 & 4 \\
\hline & so & $0.212 \pm 0.012$ & * & $0.456 \pm 0.024$ & & 14 & 3 \\
\hline & SP & $0.119 \pm 0.023$ & 7 & $0.328 \pm 0.035$ & & 17 & 5 \\
\hline \multirow{3}{*}{$\mathrm{Has}^{-/}$} & SR & $0.205 \pm 0.011$ & \multirow[b]{3}{*}{-} & $0.480 \pm 0.035$ & \multirow{3}{*}{ * } & 16 & 5 \\
\hline & so & $0.213 \pm 0.002$ & & $0.454 \pm 0.002$ & & 6 & 3 \\
\hline & SP & $0.071 \pm 0.014$ & & $0.350 \pm 0.041$ & & 22 & 5 \\
\hline
\end{tabular}

Values are expressed as mean \pm SD. SR, s. radiatum, SO, s. oriens, SP, s. pyramidale. The number of measurements was $n$ and several measurements were made in each slice. No. of slices $=$ number of mice. In SR and S0, values of $\alpha$ and $\theta$ were determined using a traditional analysis of RTI diffusion curves. There was no statistically significant difference between $S R$ and $S 0$ values of $\alpha$ and $\theta$ (Student's t test, $p>0.05$ ). Values of $\alpha$ and $\theta$ were pooled within each genotype (WT: $\alpha_{S R+S 0}=0.210, \theta_{S R+S 0}=0.465 ;$ Has3 $^{-1-}: \alpha_{S R+S 0}=0.207, \theta_{S R+S 0}=0.473$ ) and used in a multilayer analysis to extract ECS parameters for SP from RTI diffusion curves obtained across three layers (Fig. 70 ). For each ECS parameter, $\mathrm{SR}+\mathrm{SO}$ values and SP values from both genotypes were compared using two-way ANOVA followed by pairwise multiple comparison procedures. For $\alpha$, factor layer, factor genotype, and their interaction had $p<0.001$. For $\theta$, factor layer had $p<0.001$. Statistically significant difference between groups $(p<0.05)$ is marked with asterisks. No statistically significant differences were found for the nonspecific clearance $(\kappa, 5-1)$. In the WT, $\kappa$ was $0.0086 \pm 0.0014$, $0.0056 \pm 0.0011,0.0033 \pm 0.0025$ in SR, SO, and SP, respectively; and $\kappa_{\text {SR }}+$ so was 0.0070 . In Has $3^{-/} \kappa$ was $0.0028 \pm 0.0019,0.0031 \pm 0.0006,0.0079 \pm 0.0025$ in SR, S0, and SP, respectively; and $\kappa$ SR + so was 0.0029 .

the following primary antibodies: rabbit polyclonal anti-aggrecan (1:500, AB1031; Millipore), rabbit polyclonal anti-brevican (1:200; Yamada et al., 1997), mouse monoclonal anti-phosphacan (1:100, clone 3F8; Developmental Studies Hybridoma Bank), and mouse monoclonal antitenascin-R (1:100, clone 619; Synaptic Systems). For aggrecan staining, sections were preincubated with chondroitinase $\mathrm{ABC}(0.02 \mathrm{U} / \mathrm{ml}$, Seikagaku). Sections were then incubated with rhodamine Red- or Cy-2conjugated secondary antibodies (Jackson Laboratories) for $2 \mathrm{~h}$ at room temperature. After washing with PBS, sections were mounted on a glass slide with ProLong Gold medium (Life Technologies).

For NeuN staining, fresh brains were cut into 2-mm-thick coronal slices and subjected to "extracellular space-preserving fixation" (Cragg, 1980). Briefly, the slices were immersed in 0.135 Osm sodium phosphate buffer, pH 7.3, containing $2 \mathrm{~mm} \mathrm{CaCl}_{2}$ and $0.135 \mathrm{~m}$ sucrose (immersion solution) in a magnetically stirred beaker. After $2 \mathrm{~min}$, an equal volume of the fixation solution ( $8 \%$ paraformaldehyde in the immersion solution) was added over a period of $3 \mathrm{~min}$. The slices were incubated overnight at $4^{\circ} \mathrm{C}$ and then transferred to $10 \%$ and then $30 \%$ sucrose in PBS at $4^{\circ} \mathrm{C}$. From these slices, $30-\mu \mathrm{m}$-thick sections were cut on a cryostat, and free-floating sections were incubated with mouse monoclonal antiNeuN (1:100, MAB377; Millipore), followed by Cy-2-conjugated secondary antibody.

Immunofluorescence images were captured with an Olympus Fluoview Laser Point Scanning confocal microscope. Morphometric analyses of the CA1 stratum pyramidale were performed on confocal images obtained from 3 coronal hippocampal sections per mouse (between bregma levels -1.58 and $-2.06 \mathrm{~mm}$; Franklin and Paxinos, 2008) in a total of four mice for each genotype. The thickness of the hippocampal stratum pyramidale, the number and density of neurons contained within the layer, and the size of soma of pyramidal neurons were determined on $12 \mathrm{NeuN}$-stained sections per genotype ( 3 sections per animal, $4 \mathrm{WT}$ and $4 \mathrm{Has}^{-1-}$ mice) using ImageJ software. The number of PNNs was quantified in WFA-stained sections by counting the number of neuronal cell bodies surrounded by discrete PNN staining in coronal sections through the cingulate/retrospenial cortex (layers II-III, IV, and V) and through the hippocampus of WT and $\mathrm{Has}^{-1-}$ mice. Quantifications were performed on three coronal sections per mouse in a total of four mice for each genotype. Labeled cells were counted on a fluorescence microscope using a $20 \times$ objective ( 4 animals per genotype). Results were analyzed by Student's $t$ test.

Brain slice preparation. Brain slices were used for electrophysiology, imaging of extracellular marker distribution, and diffusion measurements. Altogether, coronal brain slices $400 \mu \mathrm{m}$ thick were prepared from $24 \mathrm{WT}$ and $30 \mathrm{Has}^{-1-}$ mice, as described previously (Xiao and Hrabetova, 2009; Saghyan et al., 2012). The animals were anesthetized with sodium pentobarbital ( $50 \mathrm{mg} / \mathrm{kg}$, i.p.) or halothane, and decapitated. The brain was extracted, cooled with ice-cold artificial CSF (ACSF; composition in mM: $\mathrm{NaCl} 124, \mathrm{KCl} 5, \mathrm{NaHCO}_{3} 26, \mathrm{NaH}_{2} \mathrm{PO}_{4} 1.25$, D-glucose 10,
$\mathrm{MgCl}_{2} 1.3, \mathrm{CaCl}_{2} 1.5$ ), and sliced with a vibrating blade microtome (VT 1200 S; Leica Instruments). In some experiments, only where indicated, brain slices from which the CA3 region of the hippocampus had been excised were used. For those experiments only, the CA3 region was cut out of the coronal slice in a dissecting chamber using a scalpel blade. Thereafter, the slices were held in an incubation chamber submerged in ACSF at room temperature. The ACSF was gassed with a mixture of $95 \%$ $\mathrm{O}_{2}$ and $5 \% \mathrm{CO}_{2}$ to buffer $\mathrm{pH}$ at 7.4. The ACSF osmolality, determined with a freezing point-depression osmometer (Osmette A no. 5002; Precision Systems), was $\sim 300 \mathrm{mosmol} / \mathrm{kg}$. For osmotically modified ACSF, the concentration of $\mathrm{NaCl}$ was adjusted to obtain hypertonic (400 mosmol $/ \mathrm{kg}$ ) or hypotonic (200 mosmol/kg) solutions (Kume-Kick et al., 2002).

Electrophysiology. For extracellular field recording, each brain slice was placed in a submersion recording chamber (Warner model RC-27L; Harvard Apparatus) and superfused with ACSF at a flow rate of 2.0 $\mathrm{ml} / \mathrm{min}$ delivered by a peristaltic pump. The ACSF temperature was maintained at $34 \pm 1^{\circ} \mathrm{C}$ by a dual automatic temperature controller (Warner model TC-344B; Harvard Apparatus) operating an in-line heater (Warner model SH-27A; Harvard Apparatus) in tandem with the heating element of the recording chamber. The recording chamber was placed on the fixed stage of a compound microscope (BX51WI; Olympus America) equipped with a water-immersion objective (Olympus UMPlanFl; $10 \times$, numerical aperture 0.3 ) and infrared differential interference contrast optics for visualization of the specimen and microelectrodes. The glass microelectrode for recording of extracellular field potentials was held in a robotic manipulator (MP 285; Sutter Instrument), which ensured a high precision of movement and stability. Extracellular field recordings were performed in the stratum pyramidale of the hippocampal CA1 region. In some experiments, dual extracellular field recordings were made by placing the second extracellular microelectrode in the stratum pyramidale of the hippocampal CA3 region or in the granular layer of the hippocampal dentate gyrus. The extracellular microelectrodes were filled with $150 \mathrm{~mm} \mathrm{NaCl}$. Voltage was recorded using a dualchannel microelectrode preamplifier (model IX2-700; Dagan). The signal was further amplified and low-pass filtered $(6 \mathrm{~Hz})$ using a CyberAmp 320 signal conditioner (Axon-CNS; Molecular Devices), then digitized and stored on a personal computer.

Statistical analysis of extracellular field recordings was performed using Sigma Stat 3.5 (Systat Software). In each experimental condition, the number of field potential events occurring in a $10 \mathrm{~min}$ recording segment were counted and converted to frequency in hertz. Frequency of events was used in the statistical analysis. We used the Mann-Whitney rank sum test for unpaired groups and the Wilcoxon signed rank test for paired groups. For all tests performed, $p<0.05$ was considered significant.

Simultaneous intracellular microelectrode recording and extracellular field recording was performed in five $\mathrm{Has}^{-/-}$brain slices ( 5 mice). For these experiments, each slice was placed on a net in the recording cham- 
WT

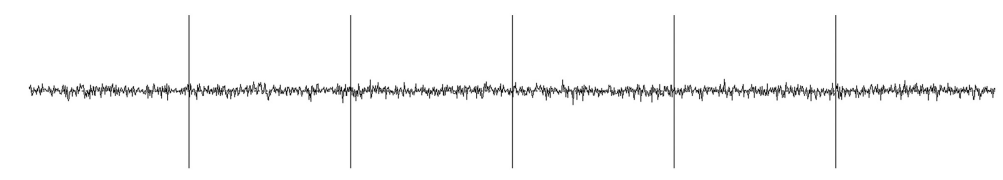

Has3 $^{-1-}$

1

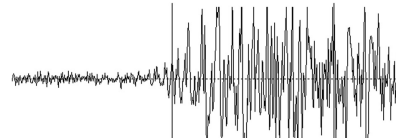

Ictal
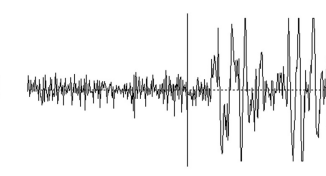

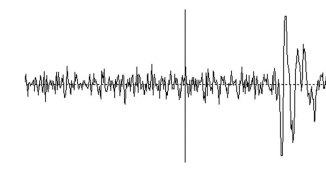
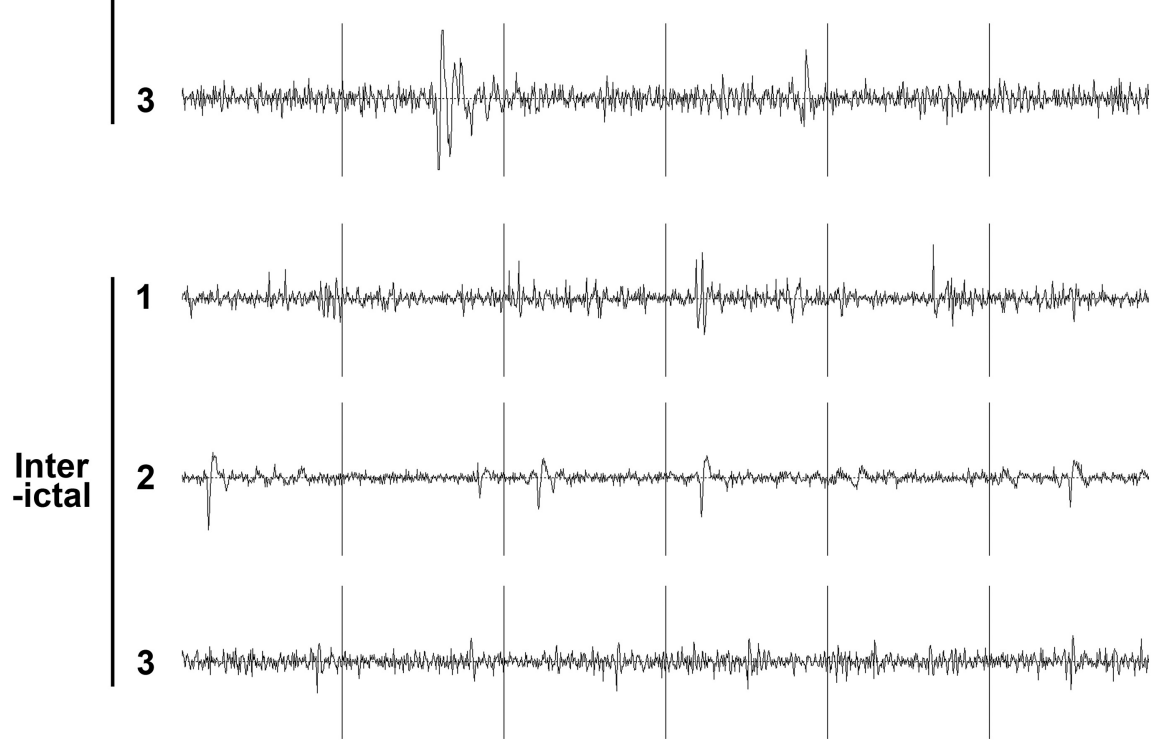

Figure 1. Spontaneous epileptic seizures in Has mutant mice. Representative tracings of electrographic seizures (Ictal) and of interictal abnormal activity (Interictal) observed in three independent $\mathrm{Has}^{-1-}$ mice are shown. A tracing of baseline EEG activity in a WT mouse is shown at the top. Spike amplitude (in microvolts on $y$-axis) is plotted as a function of recorded time course (in seconds on $x$-axis).

ber (Fine Science Tools) at an interface between humidified 95\% $\mathrm{O}_{2} / 5 \%$ $\mathrm{CO}_{2}$ gas and extracellular solution saturated with $95 \% \mathrm{O}_{2} / 5 \% \mathrm{CO}_{2}$ gas. The slice was allowed to stabilize $30 \mathrm{~min}$ to $1 \mathrm{~h}$ at $34^{\circ} \mathrm{C}$ before recording. The extracellular field recording was performed with a glass microelectrode placed at or very near the border of CA1 stratum radiatum and stratum lacunosum-moleculare. The extracellular microelectrode was filled with $150 \mathrm{~mm} \mathrm{NaCl}$ plus $3 \mathrm{~mm} \mathrm{KCl}$; the microelectrode impedance was $0.5-1.0 \mathrm{M} \Omega$ in extracellular solution. Voltage was recorded in DC using a IE-210 high-impedance amplifier at 50 times gain and further amplified at 20 times gain using a Warner LPF-100B (Harvard Apparatus). Before digitization, the voltage recording was filtered at $100 \mathrm{~Hz}$ using the low-pass Bessel filter on the Warner LPF-100B. The slices chosen for simultaneous intracellular and extracellular recording were those that had a spontaneous field potential every 5-30 s. The intracellular microelectrode was placed in CA1 stratum pyramidale as close as possible to the field microelectrode. Current-clamp recording was performed using a second high-impedance microelectrode amplifier (Warner IE-210; Harvard Apparatus). The intracellular microelectrode was filled with $3 \mathrm{~m}$ potassium acetate plus $50 \mathrm{~mm} \mathrm{KCl}$; the microelectrode impedance was 22-42 M $\Omega$. Only recordings with a resting potential of $-50 \mathrm{mV}$ or more negative, overshooting action potentials, and an input impedance of $\geq 15 \mathrm{M} \Omega$ were accepted. The input impedance of accepted cells was $22 \pm 5 \mathrm{M} \Omega$ (mean $\pm \mathrm{SD}, n=8$ ).
$500 \mu \mathrm{V}$

Before digitization, the voltage recording was filtered at $2 \mathrm{kHz}$ using the low-pass Bessel filter on the Warner IE-210. Intracellular and field potential data points were simultaneously collected at 9.5-16.7 kHz using pClamp software (Axon CNS, Molecular Devices).

Imaging of extracellular marker distribution. Experiments were performed on a recording setup equipped for imaging in brain slices. Each brain slice was placed and maintained in the same type of submersion recording chamber described in the electrophysiology section above. Imaging experiments were performed in four Has3 $3^{-1-}$ brain slices (4 mice) and in four WT brain slices (4 mice). The recording chamber was placed on the fixed stage of a compound microscope (BX61WI; Olympus America) equipped with a fluorescence illuminator system, a water-immersion objective (Olympus UMPlanFl, 10×, numerical aperture 0.3), and infrared (IR) differential interference contrast (DIC) optics for visualization of the specimen and micropipette. The glass micropipette was pulled from thin-wall glass tubing (catalog \#6170, AM System) and backfilled with fluorophore-labeled dextran (MW 3000) labeled with fluorophore Texas Red (dex3, 1 mм in 150 mм NaCl; catalog \#D-3329, Invitrogen). The tip of the micropipette, 2-4 $\mu \mathrm{m}$ in diameter, was positioned in the stratum radiatum of the hippocampal CA1 region in close proximity to the stratum pyramidale. The glass micropipette was held in a robotic manipulator (MP 285; Sutter Instrument), and the back of the micropipette was connected to a pressure pulse system (PicoSpritzer III, Parker Hannifin). The dex 3 molecules were released by a brief pressure pulse of compressed nitrogen. Dex3 distribution in the hippocampal CA1 region was imaged with a CCD camera (QuantEM 512SC, Photometrics).

RTI. The real-time iontophoretic (RTI) method (Nicholson and Phillips, 1981; Hrabetova and Nicholson, 2007) was used to quantify two parameters of ECS: volume fraction $\left(\alpha=V_{\mathrm{ECS}} / V_{\text {tissue }}\right)$ and diffusion permeability $\left(\theta=D_{\mathrm{ECS}} / D_{\text {free }}\right.$ where $D_{\mathrm{ECS}}$ is an effective diffusion coefficient in brain and $D_{\text {free }}$ is a diffusion coefficient in a medium without obstacles; Nicholson, 2001; Hrabe et al., 2004). ECS parameters in the stratum pyramidale of CA1 hippocampus were quantified using an improved multilayer analysis (Saghyan et al., 2012). The software for fitting the RTI data and for simulating diffusion using the multilayer model is available at http://claymore.rfmh.org/ lewis/programs/. In Has $3^{-1-}$ mice, diffusion measurements from slices showing rhythmic spontaneous field potentials in the CA1 region were included in the analysis. Diffusion measurements in dilute agarose gel $(0.3 \%$ in $150 \mathrm{~mm} \mathrm{NaCl}$; NuSieve GTG, FMC BioProducts) and in brain slices were performed with the same recording setup as the extracellular field recordings. Tetramethylammonium (TMA) chloride $(0.5 \mathrm{~mm})$ was added to the dilute agarose gel and the ACSF to provide a calibration standard. TMA was released by iontophoresis from a microelectrode and detected by an ion-selective microelectrode (ISM) positioned $\sim 100 \mu \mathrm{m}$ away from the source. Microelectrodes were prepared from double-barreled theta glass (Warner Instrument) as described in detail by Nicholson (1993). Both barrels of the iontophoretic microelectrode were filled with $150 \mathrm{~mm}$ TMA chloride. A continuous positive bias current of $20 \mathrm{nA}$ was applied from a constant current, high-impedance source (model ION-100; Dagan) to maintain a steady transport number $\left(n_{\mathrm{t}}\right)$ throughout the experiment. Diffusion 
curves were obtained by stepping up the iontophoretic current to $60-120 \mathrm{nA}$ for $50 \mathrm{~s}$. The TMA detecting barrel of the ISM was filled with 150 mM TMA chloride and contained a short column of tetraphenylborate based exchanger in the tip (Corning exchanger 477317; currently available as IE 190 from WPI). The reference barrel, which detected DC potential, was filled with $150 \mathrm{~mm} \mathrm{NaCl}$. Each ISM was calibrated in a set of standard solutions $(0.5,1$, 2,4 , and $8 \mathrm{~mm}$ TMA in $150 \mathrm{~mm} \mathrm{NaCl}$ ). Calibration voltages were fitted to the Nikolsky equation to obtain the slope and interference of each ISM (Nicholson, 1993). In the recording setup, the iontophoretic microelectrode and the ISM were held in robotic manipulators (MP 285; Sutter Instrument) and independently positioned in the agarose gel or the brain slice (Hrabetova et al., 2002). Slice measurements were made at a depth of $200 \mu \mathrm{m}$. The TMA signal was obtained as a difference between potentials of the detecting barrel and the reference barrel, using a dual-channel microelectrode preamplifier (model IX2-700; Dagan). The TMA signal and DC potential were amplified, low-pass filtered $(6 \mathrm{~Hz})$ using a CyberAmp 320 signal conditioner (Axon-CNS; Molecular Devices), and monitored on an analog chart recorder. Diffusion curves obtained with the RTI method in dilute agarose gel or brain slices were fitted with a solution of the diffusion equation (Nicholson and Phillips, 1981; Saghyan et al., 2012) using MATLAB (MathWorks) and Clanguage based programs. Measurements in the agarose gel yielded the transport number $n_{\mathrm{t}}$ of the iontophoretic microelectrode and the diffusion coefficient $D_{\text {agar. }}$. Dilute agarose gel was used to minimize thermal convection currents known to cause inaccuracies when water or physiological solutions are used (Nicholson, 2001). The $D_{\text {agar }}$ measured under these experimental conditions is essentially a free diffusion coefficient $D_{\text {free }}$ $\left(\mathrm{cm}^{2} / \mathrm{s}\right)$. To verify stability of the transport number throughout the experiment, additional measurements in the agarose gel were made after recording in the brain slices. Once $n_{\mathrm{t}}$ and $D_{\text {free }}$ were known, measurements in the brain slices provided estimates of the ECS volume fraction $\alpha$ $\left(\alpha=V_{\mathrm{ECS}} / V_{\text {tissue }}\right)$, effective diffusion coefficient $D_{\text {ECS }}\left(\mathrm{cm}^{2} / \mathrm{s}\right)$, and nonspecific clearance $\kappa\left(\mathrm{s}^{-1}\right)$. The nonspecific clearance quantifies loss of the diffusing substance from the ECS due to effects such as removal by the ACSF superfusing the brain slice and cellular uptake (Hrabetova and Nicholson, 2007; Kaur et al., 2008). Diffusion permeability was calculated $\left(\theta=D_{\mathrm{ECS}} / D_{\text {free }}\right.$; Hrabe et al., 2004). Diffusion records obtained with the RTI methods in the strata radiatum and oriens of the hippocampal CA1 region were processed using traditional analysis (Nicholson and Phillips, 1981). To obtain ECS parameters for the CA1 stratum pyramidale, iontophoretic and

TMA-selective microelectrodes were placed in the stratum radiatum and in the stratum oriens, respectively (Fig. 7C), and diffusion curves recorded across the three layers were processed using improved multilayer analysis (Saghyan et al., 2012). After each measurement involving the stratum pyramidale of hippocampal CA1, the thickness of the stratum pyramidale was estimated in the slice using infrared differential interference contrast (IR-DIC) optics. Sta-
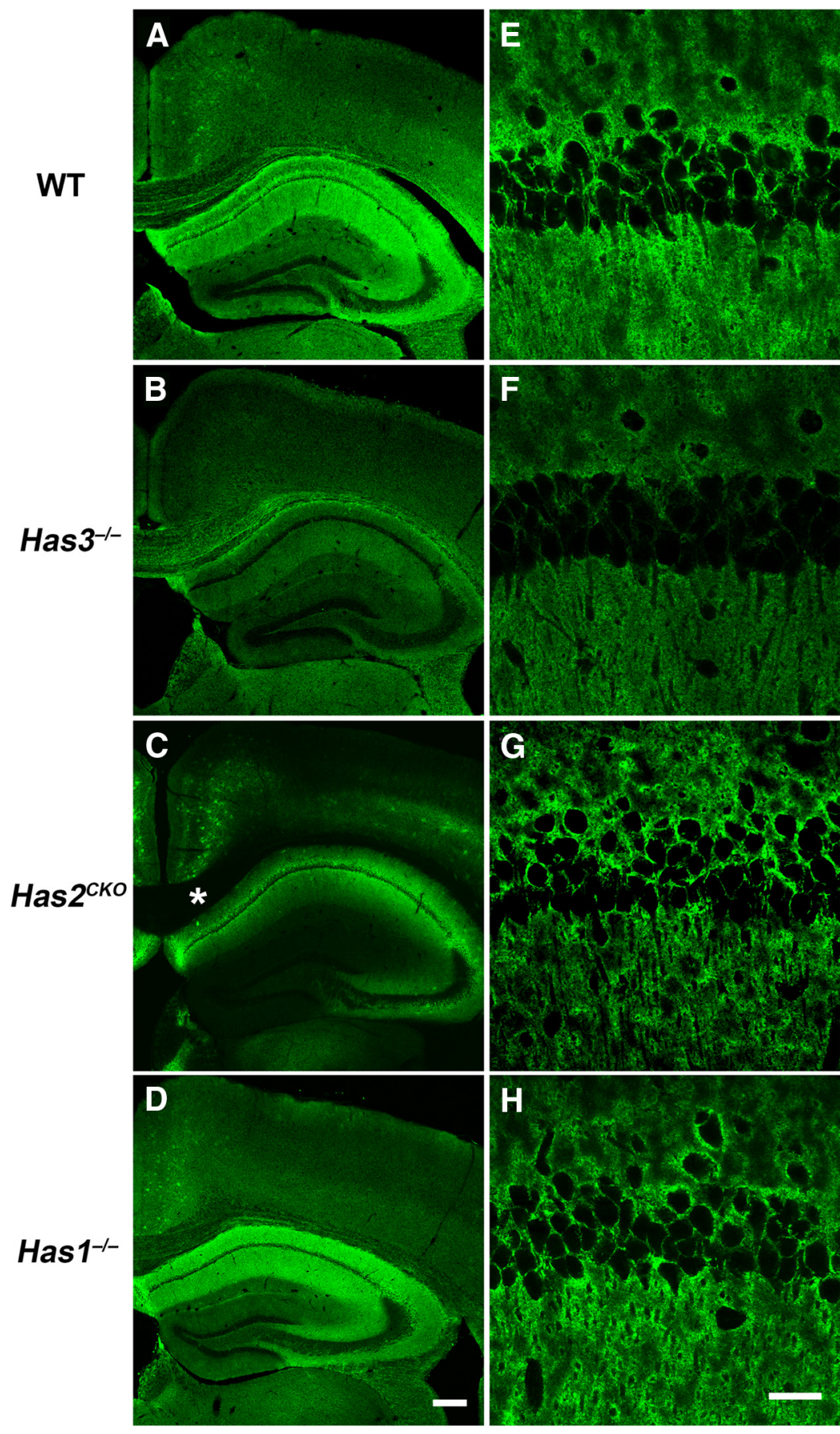

Figure 2. Spatial patterns of HA reduction in three Has mutant mouse models. Tissue staining of HA with biotinylated hyaluronan-binding protein (Laurent et al., 1991) was performed in the forebrain sections of WT $(\boldsymbol{A}, \boldsymbol{E}), \operatorname{Has}^{-1-}(\boldsymbol{B}, \boldsymbol{F})$, Has $^{\mathrm{CKO}}$ $(\boldsymbol{C}, \boldsymbol{G})$, and $\mathrm{Has}^{-1-}(\boldsymbol{D}, \boldsymbol{H})$ mice. Note that in WT mice, HA is strongly expressed in the hippocampus $(\boldsymbol{A})$. In $\operatorname{Has} 3^{-1-}$ mice, hippocampal HA staining is markedly reduced $(\boldsymbol{B})$. On the other hand, HA staining in the hippocampus is largely preserved in Has $2^{\mathrm{KO} O}$ mice (C). Instead, reduction in $\mathrm{HA}$ is prominent in the superficial layers of the cortex and in fiber tracts in $\mathrm{Has}^{\mathrm{CKO}}$ mice (e.g., the corpus callosum and the cingulum bundle; $C$, asterisk). The HA staining pattern in $\mathrm{Has}^{-1-}$ mice is essentially indistinguishable from that of WT mice (D). Scale bar, $200 \mu \mathrm{m}$. $\boldsymbol{E}-\boldsymbol{H}$, High-magnification images of the CA1 region. Note that not only is the level of $\mathrm{HA}$ staining greatly reduced in $\mathrm{Has}^{-/-}$mice, but intercellular HA staining between neurons in the stratum pyramidale is essentially lost in $\mathrm{Has}^{3-1-}$ mice $(\boldsymbol{F})$. Scale bar, $30 \mu \mathrm{m}$.

tistical analysis of $\alpha, \theta$, and $\kappa$ obtained with traditional and multilayer analyses of RTI data were performed using SigmaStat 3.5 (Systat Software). For all tests performed, $p<0.05$ was considered significant.

Multilayer diffusion analysis. Because the thickness of the stratum pyramidale is less than the microelectrode spacing used in the RTI experiments, measurements in the stratum pyramidale involved diffusion in 
A

WT
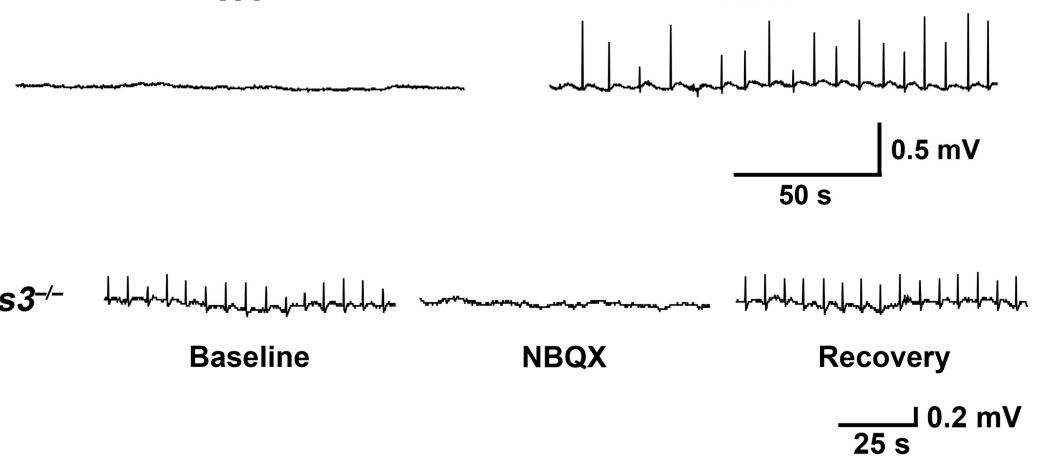

C

B
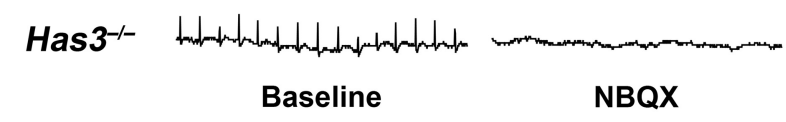

Has3 $^{-1-}$

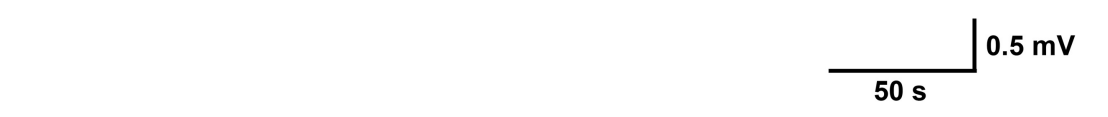

50 s

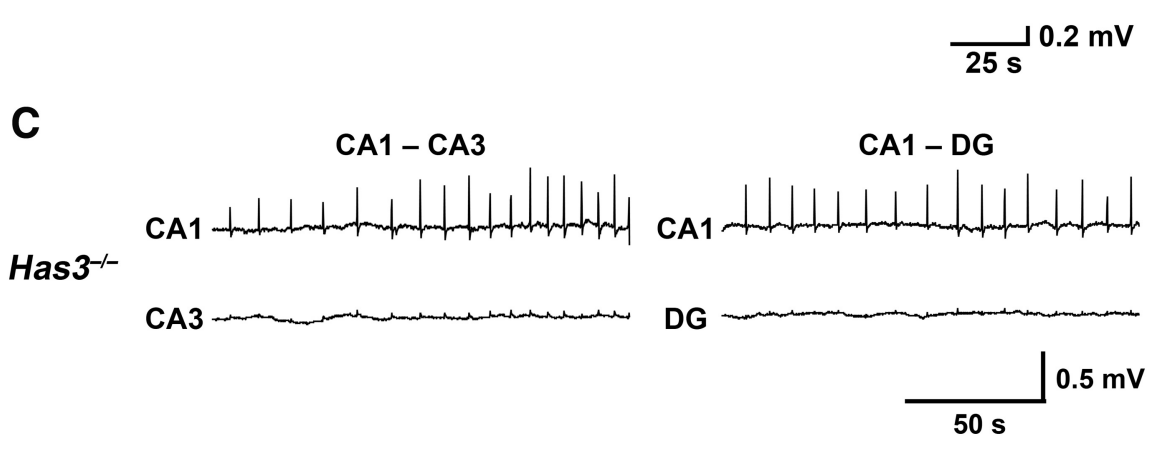

Figure 3. Spontaneous epileptiform activity in the CA1 region of $\mathrm{Has}^{-1-}$ hippocampus. $\boldsymbol{A}$, Extracellular field potential recordings in the stratum pyramidale of CA1 hippocampus in brain slices from WT and Has $3^{-1-}$ mice. No activity was found in the WT slices, whereas rhythmic spontaneous field potentials were observed in the $\mathrm{Has}^{-1-}$ slices. B. These spontaneous field potentials in the $\mathrm{Has}_{3}{ }^{-1-}$ slices were blocked by the AMPA/kainate glutamate receptor antagonist NBQX (10 $\left.\mu \mathrm{M}\right)$, and they were restored in NBQX-free ACSF. C, Extracellular recordings were made in the stratum pyramidale of the $C A 3$ region $(C A 3 ; n=5)$ and the granule cell layer of the dentate gyrus ( $D G ; n=5)$ of the hippocampal formation in $\mathrm{Has}^{-1-}$ brain slices. We found no or very small field potentials in CA3 and DG. In two of the slices, dual extracellular recordings were performed with one electrode in the stratum pyramidale of CA1 hippocampus and the other in either the stratum pyramidale of CA3 hippocampus (left) or the granule cell layer of the DG (right). Dual extracellular recordings showed rhythmic spontaneous field potentials in CA1 and much smaller field potentials, occurring synchronously with the CA1 field potentials, in CA3 and DG.

the adjacent layers as well. The ECS parameters in the stratum pyramidale were determined using the multilayer analysis method as described previously (Saghyan et al., 2012). However, two improvements were implemented. First, linear nonspecific clearance was now incorporated into the model by subtracting a term proportional to the concentration in Equation 1 (Saghyan et al., 2012):

$$
\frac{\partial c(\vec{r}, t)}{\partial t}=\frac{D_{\text {free }}}{\alpha(\vec{r})} \nabla \cdot[\alpha(\vec{r}) \boldsymbol{\theta}(\vec{r}) \cdot \nabla c(\vec{r}, t)]+\frac{s(\vec{r}, t)}{\alpha(\vec{r})}-\kappa(\vec{r}) c(\vec{r}, t)
$$

where $c(\vec{r}, t)$ is the concentration at position $\vec{r}=(x, y, z)$ and time $t, D_{\text {free }}$ is the diffusion coefficient in obstacle-free medium, $\alpha$ is the ECS volume fraction, $\boldsymbol{\theta}$ is the diffusion permeability tensor, $s$ is the source strength, and $\kappa$ is the nonspecific clearance. The boundary conditions at the interface between two layers were unchanged. Second, the RTI diffusion records were processed individually, using the pertinent values for $D_{\text {free }}$, iontophoretic current, transport number, microelectrode spacing, and thickness of the stratum pyramidale layer for each record. The parameters $\alpha, \theta$, and $\kappa$ were assumed to be constant within each layer. Averaged parameters $\alpha$ and $\theta$ obtained in stratum radiatum and stratum oriens were used in the model for these two layers (Table 3). The ECS parameters in the stratum pyramidale were determined by fitting the model to RTI data obtained with the microelectrodes on opposite sides of stratum pyramidale, as shown in Figure 7C. It was assumed that $\kappa$ was the same in all layers. The multilayer analysis thus determined the ECS parameters volume fraction $\alpha$ and diffusion permeability $\theta$ in stratum pyramidale and the global nonspecific clearance parameter $\kappa$.

The model was implemented in the $\mathrm{C}$ programming language, and all records (WT: $n=17 ;$ Has3 $^{-1-}: n=22$ ) were fitted on a 256 core high performance computing cluster. Cylindrical coordinates were used, taking advantage of the cylindrical symmetry. To reduce the number of iterations of the fitting algorithm at the full resolution of the model and thus reduce the total fitting time, we performed an initial fit at a low resolution (grid size $100 \times 200$, radial and axial dimensions) with starting values of $\alpha_{\mathrm{SP}}=0.2$, $\theta_{\mathrm{SP}}=0.4$, and $\kappa=0 \mathrm{~s}^{-1}$. The final values of these parameters for the low-resolution fit were used as the starting values for a mediumresolution fit (grid size $250 \times 500$ ). The final values of these parameters for this medium resolution fit were in turn used as starting values for the fit at the full resolution (grid size $500 \times$ 1000). Total fitting time per record ranged from $\sim 5 \mathrm{~min}$ for the low resolution fits to several days for the full resolution fits.

Simulations of extracellular diffusion. To demonstrate how the different diffusion parameters of the different layers affect extracellular concentration of a substance in the CA1 region, we used the multilayer model to run simulations of extracellular diffusion in CA1 of WT and Has $3^{-1-}$ mice. The region modeled in the simulation was an imaginary cylinder in CA1, $75 \mu \mathrm{m}$ in radius and $150 \mu \mathrm{m}$ in length, whose axis was perpendicular to the layers. Calculations were done using cylindrical coordinates to take advantage of the cylindrical symmetry, on a $600 \times 1200$ grid (radial and axial dimensions). The top, middle, and bottom $50 \mu \mathrm{m}$ of the cylinder consisted of the stratum oriens, stratum pyramidale, and stratum radiatum, respectively. Values for $\alpha, \theta$, and $\kappa$ used in the simulations were the averaged values measured in the experiments (Table 3), for $\mathrm{WT}$ and $\mathrm{Has}^{-1-}$ mice. The averaged SR + SO values were used for the stratum radiatum and stratum oriens. The free diffusion coefficient was $1.24 \times 10^{-5} \mathrm{~cm} / \mathrm{s}$ and the transport number was 0.3 , typical values measured in the experiments. In the center of each layer, an iontophoretic source of $100 \mathrm{nA}$ was applied for $1 \mathrm{~ms}$ and allowed to diffuse. The concentrations throughout the cylinder were calculated for times up to $100 \mathrm{~ms}$. Diffusion curves were generated for positions $5 \mu \mathrm{m}$ from each source (measured radially from the axis of symmetry), and an image of the concentration throughout the cylinder was generated for the time point of $10 \mathrm{~ms}$ after the start of the source.

\section{Results}

\section{Epileptic phenotypes in Has knock-out mice}

To define the physiological function of HA in the adult brain, we set out to examine neurophysiological phenotypes associated with mutant mice carrying various mutant Has alleles. We first noticed that routine animal handling, such as cage-to-cage transfer, occasionally elicited seizures in $\mathrm{Has}^{-1-} ; \mathrm{Has}^{-1-}$ compound knock-out mice. During seizures, mice typically showed tonic arching of the back and tail extension, followed by loss of posture with synchronous forelimb and hindlimb clonus for 10-15 s before starting to recover. To quantitatively analyze seizure activity, the HISS test (Todorova et al., 1999) was performed on $\mathrm{Hasl}^{-I-} ; \mathrm{Has}^{-/-}$mice $(n=40)$ and control littermates (WT; $n=29$ ) at $3-4$ months of age. This revealed that 19 of 40 Has $1^{-1-} ; \mathrm{Has}^{-1-}$ mice exhibited behavioral seizures following the HISS procedure, whereas none (0 of 29) of the WT mice underwent any seizures (Table 1).

To further characterize this seizure phenotype and dissect the contribution of the three Has isoforms, we generated mutant mice of three Has genotypes, namely $\mathrm{Hasl}^{-1-}, \mathrm{Has}^{-1-}$, and 
Has $2^{C K O}$. At 3-4 months of age, these mice were subjected to simultaneous EEG and video recording to evaluate the incidence of spontaneous seizures. This analysis revealed that seizures are most prevalent in recordings from $\mathrm{Has}^{-1-}$ mice: $56 \%(5 / 9)$ of $\mathrm{Has3}^{-1-}$ mice exhibited at least one episode of epileptic EEG bursts accompanied by behavioral seizures within the two nonconsecutive $24 \mathrm{~h}$ recordings, whereas $25 \%(2 / 8)$ of Has $2^{C K O}$ and $14 \%(1 / 7)$ of Has $1^{-1-}$ mice exhibited such episodes (Table 1 ). This result also suggests that Has3 deficiency plays a more critical role than Has1 deficiency in the seizure susceptibility of Has $1^{-1-} ; \mathrm{Has3}^{-1-}$ mice. Typical EEG abnormalities in $\mathrm{Has}^{-1-}$ mice were episodes of high-voltage polyspike bursting with a peak frequency of $4-6 \mathrm{~Hz}$ (Fig. 1). The duration, total number, and severity of electrographic events are summarized in Table 2. Electrographic abnormalities observed in Has $2^{C K O}$ and Has $1^{-1-}$ mice were generally milder than those in $\mathrm{Has}^{-1-}$ mice; episodes with highfrequency, high-voltage polyspike waves seen in $\mathrm{Has3}^{-1-}$ have never been observed in these mutants. Behaviors associated with these EEG abnormalities in Has $3^{-1-}$ mice were typically a period of behavioral arrest followed by head and forelimb clonus, sometimes showing arching of the back. Has $3^{-1-}$ mice also displayed abnormal interictal activity during normal resting behavior (Fig. 1).

\section{Different patterns of HA reduction in the brain of the three Has mutant mouse models}

Our initial histological analysis of the brains of the three Has mutants (i.e., $H a s 1^{-1-}$, Has $2^{C K O}$, and $\mathrm{Has}^{-/-}$) re-

vealed no apparent morphological defects that were thought to be causally associated with the epileptic phenotype. Thus, we sought to find a relationship between the spatial pattern of HA reduction and the severity of the epileptic phenotype among the three Has genotypes using HA staining with biotinylated HABP (Matsumoto et al., 2009).

In WT mice, HA is expressed broadly in the forebrain, and the most intense expression is seen in the hippocampus proper (Fig. $2 A, E)$. Has3 ${ }^{-1-}$ mice, which showed the strongest epileptic phenotype, exhibited a pronounced reduction in the level of HA in the hippocampus proper (Fig. $2 B, F$ ). This is in contrast to the pattern of HA reduction in $\mathrm{Has} 2^{C K O}$ mice, in which HA staining in the hippocampus proper was largely preserved (Fig. 2C,G). Instead, HA staining in the Has $2^{C K O}$ cortex was diminished more significantly compared with $\mathrm{Has}^{-1-}$ mice, and there was an almost total loss of HA along major fiber tracts, such as the corpus callosum and the cingulum bundle (Fig. $2 C$, asterisk). The HA staining in the $\mathrm{Has}^{-1-}$ brain was essentially indistinguishable from WT (Fig. $2 \mathrm{D}, H$ ), suggesting that Has1 makes no substantial contribution to HA production in the adult brain. This observa- tion is consistent with the weak epileptic phenotype of Has ${ }^{-1-}$ mice and with the much lower enzymatic activity of HAS1 compared with HAS2 and HAS3 (Itano et al., 1999). Because of the more robust epileptic phenotype in Has3 $3^{-1-}$ mice, we focused the subsequent physiological analyses on that group.

\section{Spontaneous epileptiform activity in the CA1 hippocampus of} $\mathrm{Has3}^{-1-}$ mice

To explore the neuronal activity related to the seizure phenotype observed in $\mathrm{Has}^{-1-}$ mice, we performed a series of electrophysiological experiments in the hippocampal region of $\mathrm{Has}^{-1-}$ brain slices, because this region was implicated in our HA expression experiments (Fig. 2) and is often the focus of epileptic seizures (Schwartzkroin, 1994). Rhythmic, spontaneous field potentials were routinely observed ( 17 of 19 slices, from 19 mice) in the CA1 hippocampal region of brain slices from $\mathrm{Has}^{-1-}$ mice (Fig. $3 A ; 0.11 \pm 0.05 \mathrm{~Hz}$, mean $\pm \mathrm{SD}, n=17$ slices). In addition to these rhythmic field potential events, several slices also had longer events (Fig. 4C, bottom). These longer events occurred infrequently and were of greater amplitude than the 


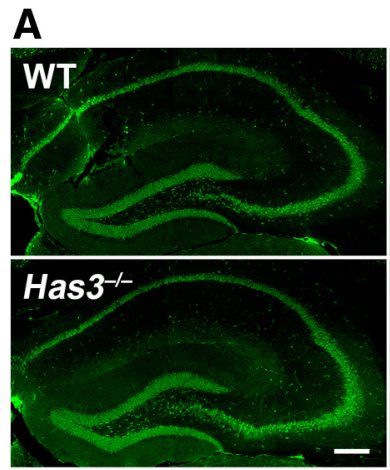

B
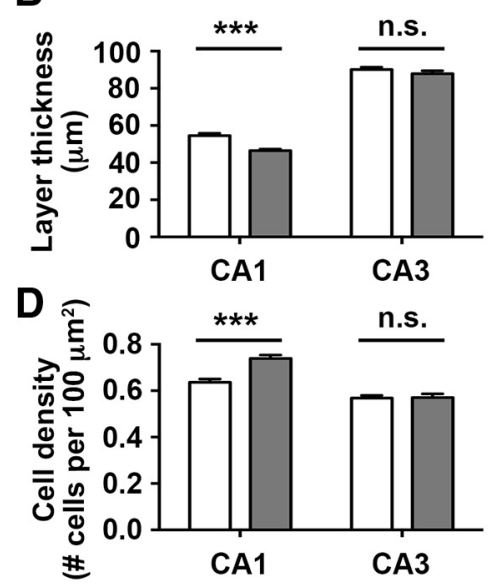

E
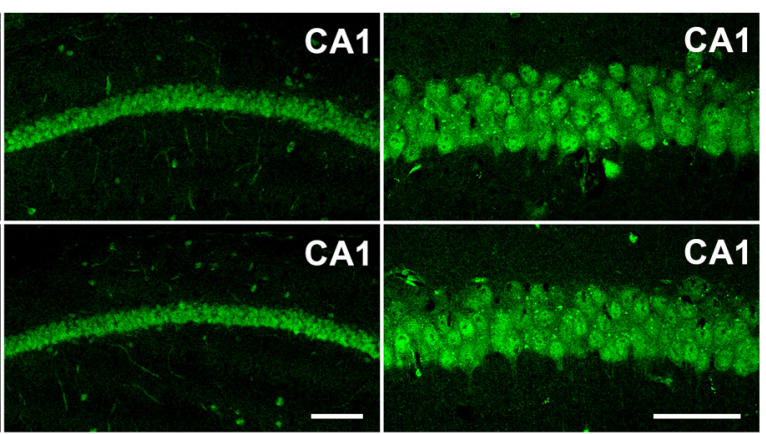

C

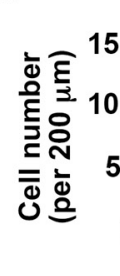

n.s.
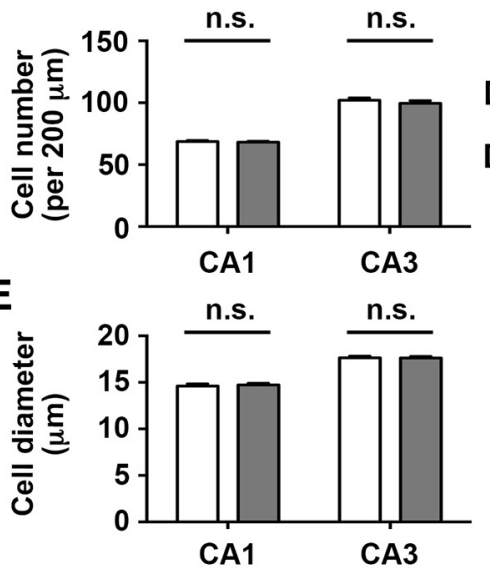

Figure 5. Increased cell packing in the CA1 stratum pyramidale of $H a s 3^{-1-}$ mice. $A$, NeuN immunostaining of the hippocampus of Has3 ${ }^{-1-}$ mice and WT littermates. Low-magnification views of hippocampus (left). Scale bar, $200 \mu \mathrm{m}$. CA1 stratum pyramidale (middle). Scale bar, $100 \mu \mathrm{m}$. High-magnification views of the CA1 (right). Scale bar, $50 \mu \mathrm{m}$. $\boldsymbol{B}-\boldsymbol{E}$, Morphometric analyses of the stratum pyramidale of $H a s 3^{-1-}$ mice and WT littermates. The thickness of the stratum pyramidale $(\boldsymbol{B})$, the number of neurons contained within the layer (per $200 \mu \mathrm{m}$ long segment; $\boldsymbol{C}$ ), the density of neurons contained within the layer (per 100 $\left.\mu \mathrm{m}^{2} ; \boldsymbol{D}\right)$, and the size of soma (longest diameter) of pyramidal neurons $(\boldsymbol{E})$ were determined in NeuN-stained sections; $n=24$ per genotype, ${ }^{* * *} p<0.001 ;$ n.s., not significant (Student's $t$ test).

rhythmic events in the same slice. In contrast, no spontaneous field potential activity was found in WT slices (Fig. 3A; $15 \mathrm{WT}$ slices, 15 mice; $0 \mathrm{~Hz}$ WT vs $0.11 \mathrm{~Hz} \mathrm{Has}^{-/-}$; $p<0.001$ by Mann-Whitney rank sum test). The rhythmic, spontaneous field potentials in $\mathrm{Has} 3^{-/-} \mathrm{CA} 1$ hippocampus were reversibly blocked by the AMPA/kainate glutamate receptor antagonist NBQX (Fig. $3 B$; 6 slices, 6 mice; $0.11 \pm 0.03 \mathrm{~Hz}$ before and $0 \mathrm{~Hz}$ after NBQX; $p<0.05$ by Wilcoxon signed rank test). Additional extracellular recordings in $\mathrm{Has}^{-1-}$ brain slices ( 5 slices, 5 mice) found very small or no spontaneous field potentials in other regions of the hippocampal formation (Fig. $3 C$ ), suggesting that the rhythmic, spontaneous field potentials in the CA1 region were initiated in a population of CA1 neurons. Further recordings from the CA1 region of $\mathrm{Has}^{-1-}$ brain slices lacking the CA3 region revealed rhythmic, spontaneous field potentials in all slices 7 slices, 7 mice; $0.10 \pm 0.04 \mathrm{~Hz}$ ), confirming that these events are generated in the CA 1 region independent of the CA3 region.

To investigate the intracellular potential and spiking activity associated with each spontaneous field potential in CA1 hippocampus, simultaneous intracellular $(n=8 \mathrm{CA} 1$ pyramidal cells in 5 slices from 5 mice) and extracellular recordings were made in $\mathrm{Has}^{-1-}$ brain slices in the interface chamber. Intracellular excitatory activity coincident with each of the rhythmic spontaneous field potentials ranged from interictal-like bursts of action potentials ( $n=2$ cells, 2 slices, 2 mice; $350-600$ ms duration; Fig. $4 A$ ) to a depolarization accompanied by $0-4$ spikes in other cells ( $n=5$ cells, 4 slices, 4 mice; Fig. $4 B)$. The eighth cell showed no spiking activity during the rhythmic, small spontaneous field potentials but showed robust, ictal-like epileptiform bursting (3-4 s duration) coincident with the infrequent, larger amplitude, longer duration field events (Fig. 4C). These recordings confirm that the spontaneous field potentials recorded in brain slices from $\mathrm{Has}^{-1-}$ mice reflect synchronous excitatory activity in a population of CA1 pyramidal cells.

\section{Increased cell packing in $\mathrm{Has}^{-/-} \mathrm{CA1}$ stratum pyramidale}

The above electrophysiological observations suggest that defects in the hippocampus underlie the epilepsy in $\mathrm{Has}^{-/-}$mice. Relevant to this possibility, we noted that the cells in the CA1 stratum pyramidale of $\mathrm{Has3}^{-1-}$ mice appeared more densely packed than normal, with much smaller spaces between cells. We therefore examined hippocampal sections, prepared using an extracellular space-preserving tissue fixation method (Cragg, 1980), by morphometric analyses. These analyses showed that the thickness of the CA1 stratum pyramidale in $\mathrm{Has}^{-1-}$ mice was decreased by $14.7 \%$ compared with WT mice (Fig. 5B, CA1; Has3 ${ }^{-1-}, 46.5 \pm 0.9$ $\mu \mathrm{m}$; WT, $54.5 \pm 1.3 \mu \mathrm{m} ; n=24 ; p<$ 0.001 by Student's $t$ test). A similar degree of reduction $(14.5 \%)$ in the thickness of the CA1 stratum pyramidale was independently demonstrated by observation in live slices under IR-DIC optics (WT: $62 \pm 4 \mu \mathrm{m}, n=17 ;$ Has3 $^{-1-}: 53 \pm 5 \mu \mathrm{m}, n=22 ; p<0.001$ by Student's $t$ test), which was performed after each RTI measurement. Although the thickness of the stratum pyramidale was decreased, there was no difference in the number of pyramidal neurons contained within this layer (Fig. 5C, CA1). This resulted in $15 \%$ higher cell density in the stratum pyramidale of $\mathrm{Has}^{-1-}$ mice (Fig. 5D, CA1; Has3 ${ }^{-1-} ; 0.739 \pm 0.015$; WT: $0.637 \pm 0.014$ cells $/ 100 \mu \mathrm{m}^{2} ; n=24 ; p<0.001$ by Student's $t$ test). Meanwhile, there was no difference in the size of individual neuronal cell bodies (Fig. 5E, CA1), suggesting that the change in cell packing is primarily due to a decrease in the size of the extracellular space. In contrast, there were no differences in any morphometric parameters in the CA3 stratum pyramidale of $\mathrm{Has}^{-I-}$ mice (Fig. $5 B-E$, $C A 3)$.

\section{$\mathrm{Has3}^{-/-}$mice display no detectable changes in} perineuronal nets

HA is a component of the PNN (Carulli et al., 2006), which is a special type of extracellular matrix associated primarily with interneurons. A paper using cultured hippocampal neurons implicated the disruption of PNNs in hyaluronidase-induced epileptiform activity (Vedunova et al., 2013). Therefore, we examined the possibility of reduced HA altering the organization of PNNs. The analysis with WFA, a general marker for PNNs, and antibodies to four major PNN components revealed no changes in the distribution and frequency of PNNs in the $\mathrm{Has}^{-1-}$ brain, 
including the hippocampus (Fig. 6A,B). Moreover, there was no detectable difference in the morphology of PNNs between WT and $\mathrm{Has}^{-1-}$ mice (Fig. 6C). These results indicate that the degree and pattern of HA depletion achieved in $\mathrm{Has}^{-1-}$ mice do not affect the assembly of PNNs, and suggest that defective PNNs are not the cause of the epileptic phenotype in Has $3^{-1-}$ mice.

\section{Reduced ECS volume fraction in the CA1 stratum pyramidale of $\mathrm{Has}^{-/-}$ mice}

Two findings in the CA1 stratum pyramidale of $\mathrm{Has}^{-1-}$ mice, namely a pronounced reduction in extracellular HA staining and an increase in cell packing, suggest that the ECS structure is altered in this layer. A previous study in rat hippocampal slices (Saghyan et al., 2012) demonstrated that transit of molecules was reduced through the CA1 stratum pyramidale because ECS volume and diffusion permeability were significantly smaller there than in the two adjacent layers. We predicted that HA deficiency would further reduce the transit of molecules through the CA1 stratum pyramidale of $\mathrm{Has}^{-1-}$ mice.

To test this hypothesis, we imaged diffusion in the CA1 hippocampus of the fluorophore-labeled extracellular marker dextran 3000 (dex3) released in the stra-

tum radiatum. We found a marked asymmetry arising at the border between the stratum radiatum and the stratum pyramidale in $\mathrm{Has}^{-1-}$ mice (Fig. 7A), indicating that the transit of dex3 through the stratum pyramidale is indeed impaired in $\mathrm{Has}^{-1-}$ mice as compared with WT mice.

To quantify this change in ECS parameters in the CA1 region, we used the RTI method (Nicholson and Phillips, 1981). Traditional analysis extracted $\alpha$ and $\theta$ in the stratum radiatum and the stratum oriens. Because the RTI method cannot measure directly in the stratum pyramidale due to the small thickness of this layer, we measured across all three layers under investigation (Fig. 7C) and used improved multilayer analysis (Saghyan et al., 2012) to obtain $\alpha$ and $\theta$ in the stratum pyramidale. We found that $\alpha$ and $\theta$ in the strata oriens and radiatum of $\mathrm{Has}^{-1-}$ mice were similar to those in the WT mice (Fig. 7B; Table 3), demonstrating that the ECS structure of the stratum oriens and the stratum radiatum remains unperturbed in $\mathrm{Has}^{-1-}$ mice. By contrast, diffusion curves recorded across the three layers in $\mathrm{Has}^{-1-}$ mice were markedly different from those of WT mice (Fig. 7C), indicating a profound change of the ECS in the stratum pyramidale of $\mathrm{Has}^{-1-}$ mice. Multilayer analysis revealed that $\alpha$ of the stratum pyramidale decreased by $\sim 40 \%$ in $\mathrm{Has}^{-1-}$ mice (Fig. $7 D$; Table 3 ), confirming a large reduction of ECS volume. On the other hand, the differences in $\theta$ were insignificant (Fig. 7D; Table 3 ). These results are consistent with an approximately uniform shrinkage of the intercellular pores of the stratum pyramidale in $\mathrm{Has}^{-1-}$ mice. The RTI experiments thus quantified our prediction of a reduced ECS volume in the CA1 stratum pyra- midale of $H a s 3^{-1-}$ mice, where epileptiform activity appears to be initiated.

Spontaneous epileptiform activity is blocked in the Has $3^{-/-}$ mice by restoration of ECS volume, and induced in the WT mice by reduction of ECS volume

Given the implied importance of ECS volume, next we asked whether its restoration in $\mathrm{Has}^{-1-}$ mice would block spontaneous epileptiform activity, and conversely, whether a reduction of the ECS volume in WT mice would induce such abnormal activity. Acute reversible changes in ECS volume fraction were induced in brain slices by osmotically modified ACSF. In Has3 $3^{-1-}$ mice, we used hypertonic $400 \mathrm{mosmol} / \mathrm{kg}$ ACSF, previously shown to increase the ECS volume by $\sim 70 \%$ (Kume-Kick et al., 2002, their Eq. 13), a relative increase needed to bring the volume fraction in stratum pyramidale from 0.07 to the 0.12 measured in WT mice under control conditions. We found that the spontaneous synchronous activity in $\mathrm{Has}^{-1-}$ mice was reversibly blocked in the hypertonic ACSF $(n=7$ slices, 7 mice; $0.11 \pm 0.04 \mathrm{~Hz}$ normal ACSF, $0 \mathrm{~Hz}$ hypertonic ACSF; Wilcoxon signed rank test, $p<0.02$; Fig. $8 A$ ).

In WT mice, we used hypotonic $200 \mathrm{mosmol} / \mathrm{kg}$ ACSF, previously shown to decrease the ECS volume by $\sim 40 \%$ (Kume-Kick et al., 2002), a relative decrease needed to bring the volume fraction in the stratum pyramidale from 0.12 to the 0.07 measured in $\mathrm{Has3}^{-1-}$ mice. We found that reversible spontaneous synchronous activity was induced in the CA1 region of slices from WT mice by hypotonic ACSF, in both whole slices $(n=7$ slices, 7 mice; $0 \mathrm{~Hz}$ normal ACSF, $0.11 \pm 0.03 \mathrm{~Hz}$ hypotonic ACSF; Wil- 
A

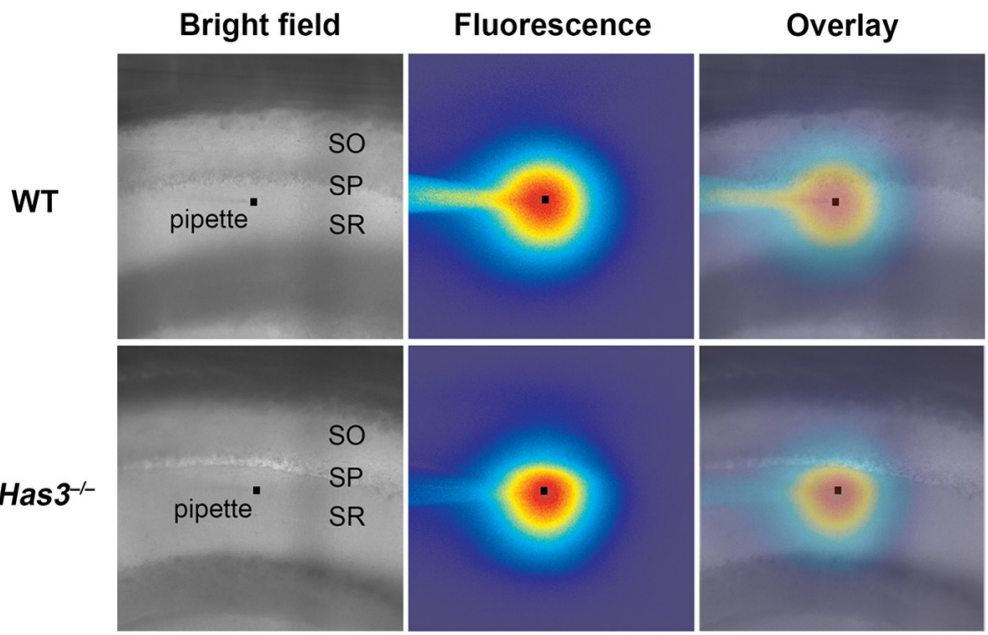

B
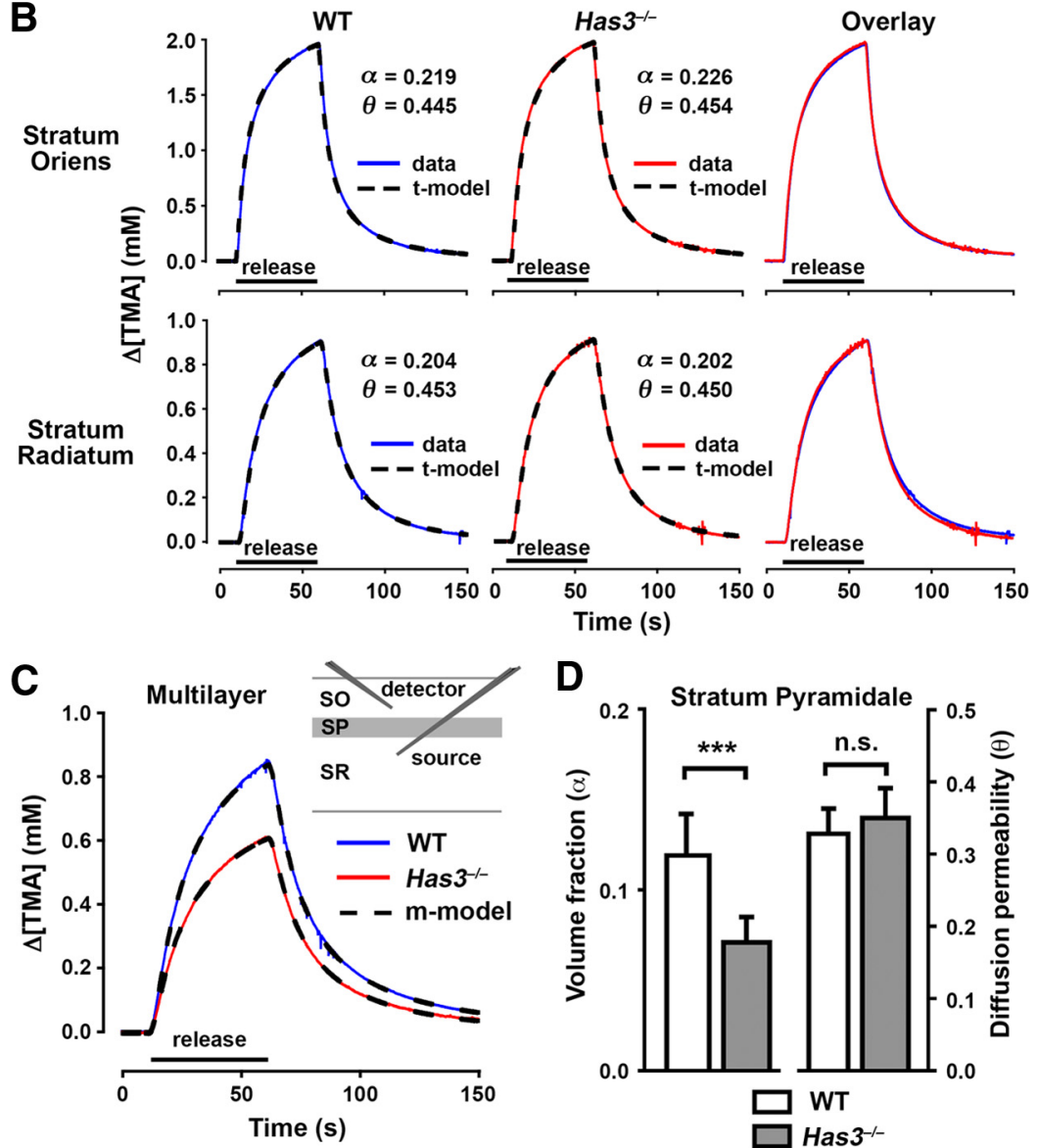

D

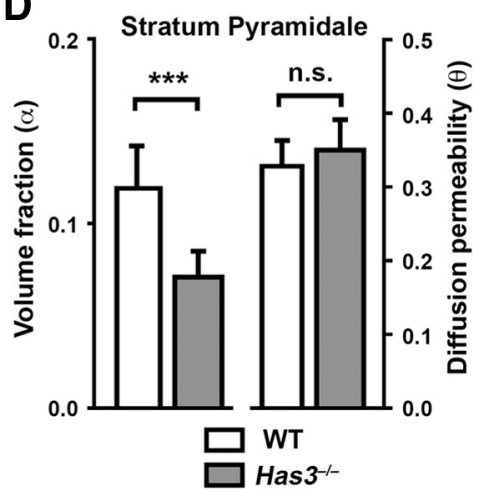

Figure 7. ECS is reduced in the CA1 stratum pyramidale in $\mathrm{Has}^{-1-}$ mice. $A$, Transit of extracellular marker molecules through the CA1 stratum pyramidale. Fluorescently labeled extracellular marker dex 3 was released by a short puff from a glass micropipette (black square denotes tip) placed in the stratum radiatum close to the border with the stratum pyramidale. Overlay of bright field and fluorescence images at $80 \mathrm{~s}$ after release. Distribution of dex 3 molecules showed an asymmetry, which was much more prominent in the $\mathrm{Has} 3^{-1-}$ mice than in the WT mice. The asymmetry arose at the border between the stratum radiatum and the stratum pyramidale. S0, stratum oriens; SP, stratum pyramidale; SR, stratum radiatum. $\boldsymbol{B}-\boldsymbol{D}$, Quantitative analysis of ECS in the CA1 hippocampus by the RTI method. $\boldsymbol{B}$, Representative examples of diffusion records from the stratum oriens and the stratum radiatum of WT and Has $3^{-1-}$ mice. TMA curves (data) fitted with traditional model curves (t-model) are shown, together with corresponding values of $\alpha$ and $\theta$. For stratum oriens, $\kappa$ was $0.0050 \mathrm{~s}^{-1}$ in WT and $0.0059 \mathrm{~s}^{-1}$ in $\mathrm{Has}^{-1-}$. For stratum radiatum, $\kappa$ was $0.0092 \mathrm{~s}^{-1}$ in WT and $0.0014 \mathrm{~s}^{-1}$ in Has $3^{-1-}$. Microelectrode spacing was 80 and $124 \mu \mathrm{m}$ for the stratum oriens records and the stratum radiatum records, respectively, and $n_{\mathrm{t}}$ was 0.31 for both records taken in the two locations. $C$, Representative examples of multilayer diffusion curves in WT and $\mathrm{Has}^{-1-}$ mice. TMA curves (WT, $\mathrm{Has}^{-1-}$ ) fitted with multilayer model curves ( $\mathrm{m}$-model) are shown, and a diagram indicates the placement of TMA-selective (detector) and iontophoretic (source) microelectrodes. Multilayer analysis was used to obtain ECS parameters for the CA1 stratum pyramidale: in WT, $\alpha=0.129, \theta=0.308$, and $\kappa=0.0039 \mathrm{~s}^{-1}$; in Has $^{-1-}, \alpha=0.073, \theta=0.297$, and $\kappa=0.0070 \mathrm{~s}^{-1}$. Microelectrode spacing was $120 \mu \mathrm{m}$ and $n_{\mathrm{t}}$ coxon signed rank test, $p<0.02$; Fig. $8 B)$ and in slices lacking the $\mathrm{CA} 3$ region $(n=7$ slices, 7 mice; $0 \mathrm{~Hz}$ normal ACSF, $0.10 \pm$ $0.03 \mathrm{~Hz}$ hypotonic ACSF; $p<0.02$ by Wilcoxon signed rank test). The epileptiform activity induced by hypotonic ACSF was blocked by the AMPA/kainate glutamate receptor antagonist NBQX $(n=6$ whole slices, 6 mice; $0.10 \pm 0.02 \mathrm{~Hz}$ before NBQX, $0 \mathrm{~Hz}$ after NBQX; $p<0.05$ by Wilcoxon signed rank test; Fig. $8 C$ ), as in $\mathrm{Has3}^{-1-}$ mice. Together, these results demonstrate that restoration of ECS volume in $\mathrm{Has}^{-1-}$ slices blocks spontaneous epileptiform activity while a reduction of ECS volume in WT slices induces it.

\section{Discussion}

In recent years, increasing attention has been focused on potential roles of matrix molecules in the regulation of neuronal function, synaptic transmission, and learning and memory (Dityatev et al., 2010; Dityatev and Rusakov, 2011). Although HA is considered to be the most abundant matrix polysaccharide in the adult brain, only a few studies have addressed the neurophysiological roles of HA or the neurological consequences of its reduction. Enzymatic disruption of the matrix with hyaluronidase was shown to affect AMPA receptor lateral diffusion (Frischknecht et al., 2009) and to modulate postsynaptic L-type calcium channels (Kochlamazashvili et al., 2010), whereas disruption of the matrix with hyaluronidase and chondroitinase impaired fear conditioning (Hylin et al., 2013). Moreover, even though previous studies have reported the effects of genetic ablation of matrix glycoproteins on neuronal function (Saghatelyan et al., 2001; Brenneke et al., 2004; Syková et al., 2005; Bekku et al., 2010), none of those ablation studies targeted HA. Our study is the first one that uses genetic ablation of HA synthesis and provides the evidence that a deficit in HA is epileptogenic in vivo.

Although all Has mutant mouse models showed increased susceptibility to epileptic seizures, the seizures were most prevalent in recordings from $\mathrm{Has}^{-1-}$ mice. Has3 ${ }^{-/-}$mice also showed a pronounced reduction in hippocampal HA

$\leftarrow$

was 0.33 for both records taken in the two genotypes. $D$, Summary of ECS volume fraction and diffusion permeability values in the stratum pyramidale of WT and $\mathrm{Has}^{-1-}$ mice. ECS volume fraction was reduced by $40 \%$ in $\mathrm{Has}^{-1-}$ mice, whereas diffusion permeability was not changed (Table 3 shows statistical analysis and values of $\kappa$ ). Data are expressed as mean \pm SD. 
that was not seen in the other mice. This difference in the prevalence of the epilepsy phenotype most likely reflects the expression pattern of each Has gene. Although the possibility remains that HA synthesized by HAS3 may be functionally distinct, this does not seem likely because each of the Has enzymes possesses both the $N$-acetylglucosaminyltransferase and glucuronyltransferase activities necessary for the synthesis of complete HA (Itano et al., 1999).

Based on the analysis of the spatial expression pattern of $\mathrm{HA}$ in three Has knock-out mouse models, we hypothesized that a change in the ECS in the hippocampus is the key mechanism underlying the epileptic phenotype in these mice. Results from our multidisciplinary analyses supported the hypothesis and revealed the role of $\mathrm{HA}$ in regulating brain ECS. Most importantly, both the imaging of extracellular markers and the quantitative diffusion analysis in $\mathrm{Has}^{-1-}$ mice identified a substantial reduction in the ECS volume in the CA1 stratum pyramidale. The CA1 stratum pyramidale was also the location that had a near total loss in HA staining and a significant increase in cell packing in $\mathrm{Has}^{-1-}$ mice. Furthermore, electrophysiological analyses demonstrated epileptiform activity in the CA 1 stratum pyramidale. Together, these results suggested that the reduction of ECS volume in the CA1 stratum pyramidale is the key defect underlying the epileptic phenotype of $\mathrm{Has3}^{-1-}$ mice, and the osmotic experiments supported that conclusion.

In accord with our finding of increased seizure susceptibility and reduced ECS volume in $\mathrm{Has}^{-1-}$ mice, decreased seizure susceptibility and enlarged ECS volume were previously reported in aquaporin-4-deficient mice (Binder et al., 2004; Yao et al., 2008). We also note that other studies have demonstrated modulation of ongoing epileptiform activity by osmotically induced ECS volume changes (Andrew et al., 1989; Traynelis and Dingledine, 1989; Dudek et al., 1998). Our osmotic experiments go further because we show that an ECS volume reduction can actually initiate epileptiform activity, and our Has3 knock-out experiments extend that finding to show that a highly localized volume reduction can cause epileptiform activity.

Previous studies provide independent support for the role of reduced ECS volume in seizure promotion. It has been proposed that the regional variation of the ECS properties in hippocampus underlies the susceptibility of the CA1 region to seizure-like activity (McBain et al., 1990). RTI
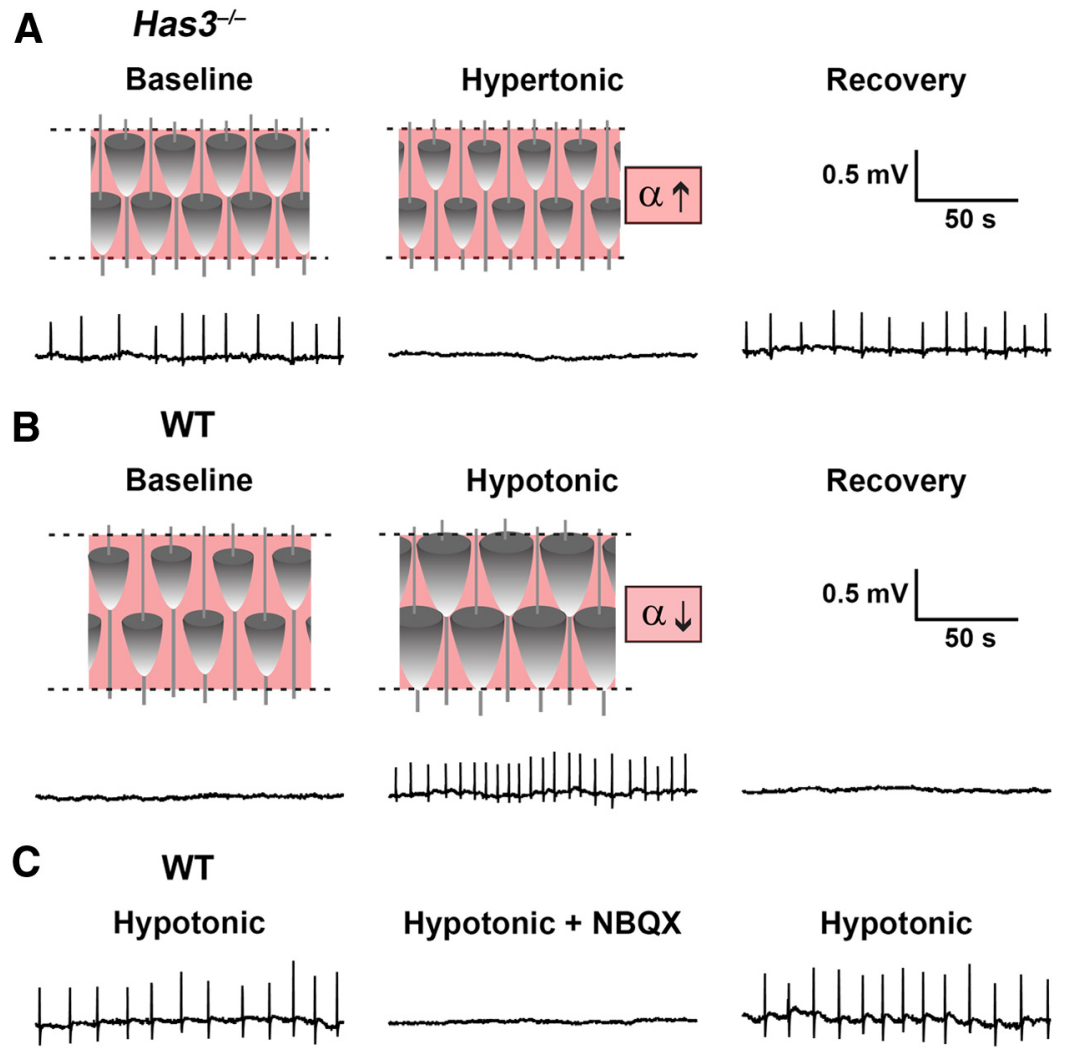

Figure 8. Restoration of ECS volume in Has $3^{-/-}$slices blocks spontaneous epileptiform activity, whereas reduction of ECS volume in WT slices mimics Has $3^{-/-}$phenotype. $A$, In Has $3^{-1-}$ slices, hypertonic conditions ( $400 \mathrm{mosmol} / \mathrm{kg}$ ) were used to shift water from the intra- to the extracellular compartment and increase ECS volume fraction $\alpha$. This manipulation reversibly blocked spontaneous epileptiform activity in the CA1 hippocampus. B, In WT slices, hypotonic conditions (200 mosmol/kg) were used to shift water from the extracellular to the intracellular compartment and decrease the ECS volume fraction. This manipulation induced spontaneous epileptiform activity in the CA1 hippocampus, which was blocked upon return to normo-osmotic ACSF. C, Epileptiform activity induced in WT brain slices was reversibly blocked by NBQX. This NBQX sensitivity was also observed in $\mathrm{Has}^{-1-}$ slices (Fig. 3B). Field potential recordings were made with electrode placed in the CA1 stratum pyramidale.
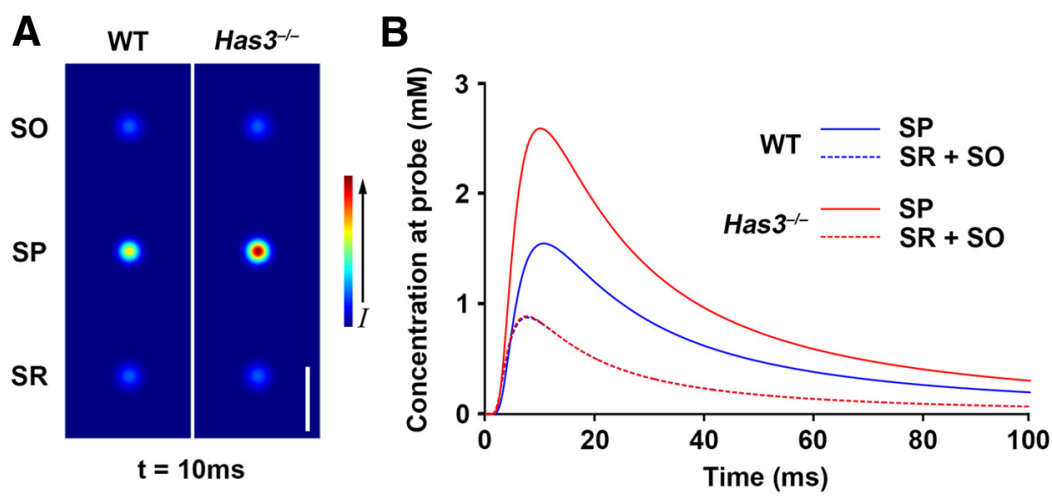

Figure 9. Simulations of diffusion in the ECS of the CA1 hippocampus in WT and Has3 $3^{-1-}$ mice. In these simulations, informed by our results on ECS parameters in individual layers, molecules were released for $1 \mathrm{~ms}$ from point sources in the center of each layer and allowed to diffuse. The same number of molecules was released into each layer. $\boldsymbol{A}$, Images show concentration of diffusing molecules at $10 \mathrm{~ms}$ after the start of the release. Concentration is higher in the stratum pyramidale of Has $3^{-1-}$ mice than in that of WT mice because of the reduced ECS volume fraction. Scale bar, $25 \mu \mathrm{m}$. $\boldsymbol{B}$, Concentration versus time profiles at a distance of 5 $\mu \mathrm{m}$ from each point source (measured radially from axis of symmetry). Simulations show that the concentration of a substance released into stratum pyramidale will stay higher longer in $\mathrm{Has} 3^{-1-}$ than in WT mice, and that a larger number of cells will simultaneously be exposed to the released substance.

experiments in rat hippocampus showed that even under normal conditions, the CA1 stratum pyramidale has significantly lower ECS volume than the two adjacent layers (McBain et al., 1990; Saghyan et al., 2012). Tissue resistance measurements also 
demonstrated a gradual reduction of the ECS volume in CA1 stratum pyramidale immediately preceding a seizure (Traynelis and Dingledine, 1989), suggesting that the seizure was precipitated by a further reduction of an already low ECS volume in the CA1 stratum pyramidale.

Despite the fact that the epileptiform activity in $\mathrm{Has}^{-1-}$ mice is dependent upon glutamate-mediated synaptic transmission, our data do not support the hypothesis that a developmental change in glutamate-mediated synaptic transmission is responsible for the epileptogenesis. First, a very similar NBQX-sensitive and CA3-independent epileptiform activity could be induced in the CA1 hippocampal region of brain slices from WT mice by acutely reducing ECS volume via osmotic manipulation. Second, the in vitro epileptiform phenotype in $\mathrm{Has}^{-I-}$ slices could be rescued by acutely increasing ECS volume. Furthermore, as excising the CA3 region did not affect the epileptiform activity recorded in the CA1 region of $\mathrm{Has}^{-1-}$ mice, the data do not support the hypothesis that an increase in synaptic transmission at the Schaffer collateral input from CA3 pyramidal cells to CA1 pyramidal cells is responsible for the epileptiform activity. Finally, a recent in vitro study using enzymatic degradation of HA in dissociated neurons (Vedunova et al., 2013) suggests the possibility that epileptogenesis in the absence of HA is mediated by the disruption of PNNs. Our results, however, revealed no detectable changes in the structure or composition of PNNs in Has3 ${ }^{-1-}$ mice (Fig. 6). Thus, it is unlikely that functional alterations in PNNs are the primary cause of the epileptic phenotype in Has $3^{-1-}$ mice.

From the biochemical and biophysical points of view, it is not surprising that a consequence of the reduction in HA is a reduction in ECS volume: with its pronounced hydration capacity, HA occupies a very large molecular domain in solution, unparalleled by any other matrix macromolecule (Toole, 2004). How does this ECS volume reduction lead to epilepsy? Our results from the RTI experiments indicate an approximately uniform shrinkage of the ECS of the stratum pyramidale in $\mathrm{Has}^{-1-}$ mice. Thus, one possibility is that ECS volume reduction in the stratum pyramidale alters the spatiotemporal distribution of neuroactive substances such that a larger number of pyramidal cells simultaneously experience higher concentrations of any released substance. In fact, our simulation model of extracellular diffusion within the stratum pyramidale predicts such an effect in the $\mathrm{Has}^{-1-}$ hippocampus (Fig. 9). This effect may be particularly relevant for $\mathrm{K}^{+}$, which is released from firing neurons. Because of the reduced ECS volume, $\mathrm{K}^{+}$released from an active CA1 pyramidal cell body in the $\mathrm{Has}^{-1-}$ brain would be more likely to induce depolarization and firing in neighboring cells, and thereby promote synchronous activity. A second possible mechanism is the increased likelihood of electric field effects and ephaptic interactions: close apposition of membranes of CA1 pyramidal cell bodies may increase the effect of extracellular currents, enabling depolarization in one cell to induce depolarization in neighboring cells (Jefferys, 1995), resulting in an increased population of synchronously excited cells. Either of these possible explanations suggests that nonsynaptic mechanisms acting on the somatic compartment of CA1 pyramidal neurons play a key role in epileptogenesis in $\mathrm{Has}^{-1-}$ mice.

In conclusion, this study demonstrates that the ablation of Has3-dependent HA causes reduced ECS volume in the CA1 stratum pyramidale, epileptiform activity in the CA1 region, and epileptic seizures in the mutant mouse. Although the possibility that Has genes may be involved in the pathogenesis of human epilepsy has yet to be explored, it is interesting to note that an acute CNS injury, which can trigger epileptogenesis (Lowenstein, 2009), also activates the expression of hyaluronidase (Sherman et al., 2002) and the generation of reactive oxygen species (GilgunSherki et al., 2002), both of which cause HA degradation (Bates et al., 1984). Our finding linking a loss of HA to epileptogenesis thus may open an avenue for development of new antiepileptogenic therapies based on the inhibition of HA degradation.

\section{References}

Andrew RD, Fagan M, Ballyk BA, Rosen AS (1989) Seizure susceptibility and the osmotic state. Brain Res 498:175-180. CrossRef Medline

Bai KJ, Spicer AP, Mascarenhas MM, Yu L, Ochoa CD, Garg HG, Quinn DA (2005) The role of hyaluronan synthase 3 in ventilator-induced lung injury. Am J Respir Crit Care Med 172:92-98. CrossRef Medline

Baraban SC, Southwell DG, Estrada RC, Jones DL, Sebe JY, Alfaro-Cervello C, García-Verdugo JM, Rubenstein JL, Alvarez-Buylla A (2009) Reduction of seizures by transplantation of cortical GABAergic interneuron precursors into Kv1.1 mutant mice. Proc Natl Acad Sci U S A 106:15472-15477. CrossRef Medline

Bates EJ, Harper GS, Lowther DA, Preston BN (1984) Effect of oxygenderived reactive species on cartilage proteoglycan-hyaluronate aggregates. Biochem Int 8:629-637. Medline

Bekku Y, Vargová L, Goto Y, Voříšek I, Dmytrenko L, Narasaki M, Ohtsuka A, Fässler R, Ninomiya Y, Syková E, Oohashi T (2010) Brall: its role in diffusion barrier formation and conduction velocity in the CNS. J Neurosci 30:3113-3123. CrossRef Medline

Binder DK, Oshio K, Ma T, Verkman AS, Manley GT (2004) Increased seizure threshold in mice lacking aquaporin-4 water channels. Neuroreport 15:259-262. CrossRef Medline

Brenneke F, Bukal O, Dityatev A, Lie AA (2004) Mice deficient for the extracellular matrix glycoprotein tenascin-r show physiological and structural hallmarks of increased hippocampal excitability, but no increased susceptibility to seizures in the pilocarpine model of epilepsy. Neuroscience 124:841-855. CrossRef Medline

Camenisch TD, Spicer AP, Brehm-Gibson T, Biesterfeldt J, Augustine ML, Calabro A Jr, Kubalak S, Klewer SE, McDonald JA (2000) Disruption of hyaluronan synthase-2 abrogates normal cardiac morphogenesis and hyaluronan-mediated transformation of epithelium to mesenchyme. J Clin Invest 106:349-360. CrossRef Medline

Carulli D, Rhodes KE, Brown DJ, Bonnert TP, Pollack SJ, Oliver K, Strata P, Fawcett JW (2006) Composition of perineuronal nets in the adult rat cerebellum and the cellular origin of their components. J Comp Neurol 494:559-577. CrossRef Medline

Cragg B (1980) Preservation of extracellular space during fixation of the brain for electron microscopy. Tissue Cell 12:63-72. CrossRef Medline

Dityatev A, Rusakov DA (2011) Molecular signals of plasticity at the tetrapartite synapse. Curr Opin Neurobiol 21:353-359. CrossRef Medline

Dityatev A, Schachner M, Sonderegger P (2010) The dual role of the extracellular matrix in synaptic plasticity and homeostasis. Nat Rev Neurosci 11:735-746. CrossRef Medline

Dudek FE, Yasumura T, Rash JE (1998) 'Non-synaptic' mechanisms in seizures and epileptogenesis. Cell Biol Int 22:793-805. CrossRef Medline

Franklin KBJ, Paxinos G (2008) The mouse brain in stereotaxic coordinates, Ed 3. San Diego: Elsevier Academic.

Fraser JR, Laurent TC, Laurent UB (1997) Hyaluronan: its nature, distribution, functions and turnover. J Intern Med 242:27-33. CrossRef Medline

Frischknecht R, Heine M, Perrais D, Seidenbecher CI, Choquet D, Gundelfinger ED (2009) Brain extracellular matrix affects AMPA receptor lateral mobility and short-term synaptic plasticity. Nat Neurosci 12 : 897-904. CrossRef Medline

Gilgun-Sherki Y, Rosenbaum Z, Melamed E, Offen D (2002) Antioxidant therapy in acute central nervous system injury: current state. Pharmacol Rev 54:271-284. CrossRef Medline

Hrabe J, Hrabetova S, Segeth K (2004) A model of effective diffusion and tortuosity in the extracellular space of the brain. Biophys J 87:1606-1617. CrossRef Medline

Hrabetova S, Nicholson C (2007) Eletrochemical methods for neuroscience. Boca Raton, FL: CRC.

Hrabetova S, Chen KC, Masri D, Nicholson C (2002) Water compartmentalization and spread of ischemic injury in thick-slice ischemia model. J Cereb Blood Flow Metab 22:80-88. CrossRef Medline 
Hylin MJ, Orsi SA, Moore AN, Dash PK (2013) Disruption of the perineuronal net in the hippocampus or medial prefrontal cortex impairs fear conditioning. Learn Mem 20:267-273. CrossRef Medline

Itano N, Sawai T, Yoshida M, Lenas P, Yamada Y, Imagawa M, Shinomura T, Hamaguchi M, Yoshida Y, Ohnuki Y, Miyauchi S, Spicer AP, McDonald JA, Kimata K (1999) Three isoforms of mammalian hyaluronan synthases have distinct enzymatic properties. J Biol Chem 274:25085-25092. CrossRef Medline

Jefferys JG (1995) Nonsynaptic modulation of neuronal activity in the brain: electric currents and extracellular ions. Physiol Rev 75:689-723. Medline

Kaur G, Hrabetova S, Guilfoyle DN, Nicholson C, Hrabe J (2008) Characterizing molecular probes for diffusion measurements in the brain. J Neurosci Methods 171:218-225. CrossRef Medline

Kochlamazashvili G, Henneberger C, Bukalo O, Dvoretskova E, Senkov O, Lievens PM, Westenbroek R, Engel AK, Catterall WA, Rusakov DA, Schachner M, Dityatev A (2010) The extracellular matrix molecule hyaluronic acid regulates hippocampal synaptic plasticity by modulating postsynaptic L-type $\mathrm{Ca}(2+)$ channels. Neuron 67:116-128. CrossRef Medline

Kume-Kick J, Mazel T, Voříšek I, Hrabĕtova S, Tao L, Nicholson C (2002) Independence of extracellular tortuosity and volume fraction during osmotic challenge in rat neocortex. J Physiol 542:515-527. CrossRef Medline

Laurent C, Johnson-Wells G, Hellström S, Engström-Laurent A, Wells AF (1991) Localization of hyaluronan in various muscular tissues: a morphological study in the rat. Cell Tissue Res 263:201-205. CrossRef Medline

Lowenstein DH (2009) Epilepsy after head injury: an overview. Epilepsia 50:4-9. CrossRef Medline

Mack JA, Feldman RJ, Itano N, Kimata K, Lauer M, Hascall VC, Maytin EV (2012) Enhanced inflammation and accelerated wound closure following tetraphorbol ester application or full-thickness wounding in mice lacking hyaluronan synthases Has1 and Has3. J Invest Dermatol 132:198207. CrossRef Medline

Margineanu DG (2010) Epileptic hypersynchrony revisited. Neuroreport 21:963-967. CrossRef Medline

Matsumoto K, Li Y, Jakuba C, Sugiyama Y, Sayo T, Okuno M, Dealy CN, Toole BP, Takeda J, Yamaguchi Y, Kosher RA (2009) Conditional inactivation of Has 2 reveals a crucial role for hyaluronan in skeletal growth, patterning, chondrocyte maturation and joint formation in the developing limb. Development 136:2825-2835. CrossRef Medline

McBain CJ, Traynelis SF, Dingledine R (1990) Regional variation of extracellular space in the hippocampus. Science 249:674-677. CrossRef Medline

Nicholson C (1993) Ion-selective microelectrodes and diffusion measurements as tools to explore the brain cell microenvironment. J Neurosci Methods 48:199-213. CrossRef Medline

Nicholson C (2001) Diffusion and related transport mechanisms in brain tissue. Rep Prog Phys 64:815-884. CrossRef
Nicholson C, Phillips JM (1981) Ion diffusion modified by tortuosity and volume fraction in the extracellular microenvironment of the rat cerebellum. J Physiol 321:225-257. Medline

Saghatelyan AK, Dityatev A, Schmidt S, Schuster T, Bartsch U, Schachner M (2001) Reduced perisomatic inhibition, increased excitatory transmission, and impaired long-term potentiation in mice deficient for the extracellular matrix glycoprotein tenascin-R. Mol Cell Neurosci 17:226-240. CrossRef Medline

Saghyan A, Lewis DP, Hrabe J, Hrabetova S (2012) Extracellular diffusion in laminar brain structures exemplified by hippocampus. J Neurosci Methods 205:110-118. CrossRef Medline

Schwartzkroin PA (1994) Role of the hippocampus in epilepsy. Hippocampus 4:239-242. CrossRef Medline

Sherman LS, Struve JN, Rangwala R, Wallingford NM, Tuohy TM, Kuntz C 4th (2002) Hyaluronate-based extracellular matrix: keeping glia in their place. Glia 38:93-102. CrossRef Medline

Syková E, Nicholson C (2008) Diffusion in brain extracellular space. Physiol Rev 88:1277-1340. CrossRef Medline

Syková E, Voříšek I, Mazel T, Antonova T, Schachner M (2005) Reduced extracellular space in the brain of tenascin-R- and HNK-1-sulphotransferase deficient mice. Eur J Neurosci 22:1873-1880. CrossRef Medline

Todorova MT, Burwell TJ, Seyfried TN (1999) Environmental risk factors for multifactorial epilepsy in EL mice. Epilepsia 40:1697-1707. CrossRef Medline

Toole BP (2000) Hyaluronan is not just a goo! J Clin Invest 106:335-336. CrossRef Medline

Toole BP (2004) Hyaluronan: from extracellular glue to pericellular cue. Nat Rev Cancer 4:528-539. CrossRef Medline

Traynelis SF, Dingledine R (1989) Role of extracellular space in hyperosmotic suppression of potassium-induced electrographic seizures. J Neurophysiol 61:927-938. Medline

Tronche F, Kellendonk C, Kretz O, Gass P, Anlag K, Orban PC, Bock R, Klein R, Schütz G (1999) Disruption of the glucocorticoid receptor gene in the nervous system results in reduced anxiety. Nat Genet 23:99-103. CrossRef Medline

Vedunova M, Sakharnova T, Mitroshina E, Perminova M, Pimashkin A, Zakharov Y, Dityatev A, Mukhina I (2013) Seizure-like activity in hyaluronidase-treated dissociated hippocampal cultures. Front Cell Neurosci 7:149. CrossRef Medline

Xiao F, Hrabetova S (2009) Enlarged extracellular space of aquaporin-4deficient mice does not enhance diffusion of AlexaFluor 488 or dextran polymers. Neuroscience 161:39-45. CrossRef Medline

Yamada H, Fredette B, Shitara K, Hagihara K, Miura R, Ranscht B, Stallcup WB, Yamaguchi Y (1997) The brain chondroitin sulfate proteoglycan brevican associates with astrocytes ensheathing cerebellar glomeruli and inhibits neurite outgrowth from granule neurons. J Neurosci 17:77847795. Medline

Yao X, Hrabetova S, Nicholson C, Manley GT (2008) Aquaporin-4deficient mice have increased extracellular space without tortuosity change. J Neurosci 28:5460-5464. CrossRef Medline 